\title{
AN EMPIRICAL STUDY OF THE EFFECTS OF OPEN SOURCE ADOPTION ON SOFTWARE DEVELOPMENT ECONOMICS
}

by

$\mathrm{Di} \mathrm{Wu}$

\begin{abstract}
A thesis submitted to the Faculty of Graduate Studies and Research in partial fulfillment of the requirements for the degree of Master of Applied Science in Technology Innovation Management
\end{abstract}

\author{
Department of Systems and Computer Engineering, \\ Carleton University \\ Ottawa, Canada, K1S 5B6
}

March 2007

(C) Copyright $2007 \mathrm{Di} \mathrm{Wu}$ 


$\begin{array}{ll}\begin{array}{l}\text { Library and } \\ \text { Archives Canada }\end{array} & \begin{array}{l}\text { Bibliothèque et } \\ \text { Archives Canada }\end{array} \\ \begin{array}{l}\text { Published Heritage } \\ \text { Branch }\end{array} & \begin{array}{l}\text { Direction du } \\ \text { Patrimoine de l'édition }\end{array} \\ \begin{array}{l}\text { 395 Wellington Street } \\ \text { Ottawa ON K1A 0N4 }\end{array} & \begin{array}{l}\text { 395, rue Wellington } \\ \text { Ottana ON K1A ON4 } \\ \text { Canada Oa }\end{array}\end{array}$

Your file Votre référence ISBN: 978-0-494-27005-9 Ourfile Notre référence ISBN: 978-0-494-27005-9

NOTICE:

The author has granted a nonexclusive license allowing Library and Archives Canada to reproduce, publish, archive, preserve, conserve, communicate to the public by telecommunication or on the Internet, loan, distribute and sell theses worldwide, for commercial or noncommercial purposes, in microform, paper, electronic and/or any other formats.

The author retains copyright ownership and moral rights in this thesis. Neither the thesis nor substantial extracts from it may be printed or otherwise reproduced without the author's permission.
AVIS:

L'auteur a accordé une licence non exclusive permettant à la Bibliothèque et Archives Canada de reproduire, publier, archiver, sauvegarder, conserver, transmettre au public par télécommunication ou par l'Internet, prêter, distribuer et vendre des thèses partout dans le monde, à des fins commerciales ou autres, sur support microforme, papier, électronique et/ou autres formats.

L'auteur conserve la propriété du droit d'auteur et des droits moraux qui protège cette thèse. $\mathrm{Ni}$ la thèse ni des extraits substantiels de celle-ci ne doivent être imprimés ou autrement reproduits sans son autorisation.
In compliance with the Canadian

Privacy Act some supporting forms may have been removed from this thesis.

While these forms may be included in the document page count, their removal does not represent any loss of content from the thesis.
Conformément à la loi canadienne sur la protection de la vie privée, quelques formulaires secondaires ont été enlevés de cette thèse.

Bien que ces formulaires aient inclus dans la pagination, il n'y aura aucun contenu manquant. 


\begin{abstract}
This research presents the results of empirical study of the effects of open source software (OSS) adoption on software development economics. Specifically, we examined three economic factors - cost, productivity, and quality. This study started with an extensive literature review followed by an exploratory study conducted through interviews with 18 senior project/quality managers, and senior software developers. Then, the result of the literature review and the exploratory study was used to formulate research model, hypotheses, and survey questionnaire. Software intensive companies from Canada and the U.S. were targeted for this study. The period of study was between September 2004 and March 2006. Our findings show that there are strong significant statistical correlations between the factors of OSS adoption and software development economics. The conclusion from this study shows that software organizations can achieve some economic gains in terms of software development productivity and product quality if they implement OSS adoption in a systematic way. A big lesson learned in this study is that OSS are of highest quality and that open source community is not setting a bad example (contrary to some opinion) so far as 'good practices' are concerned.
\end{abstract}




\section{ACKNOWLEDGEMENTS}

First of all, I would like to thank Professor Samuel A. Ajila, my thesis supervisor for his guidance, encouragement and continuing support during the development and completion of this thesis.

I also appreciate Professor Tony Bailetti and John Callahan for their advice and suggestions for my research.

Then, I would like to express my deepest gratitude to all the people who filled the questionnaires for my research.

Finally, I thank my family, especially my parents for their understanding, unconditional support and continuous encouragement in the process of writing this thesis. 


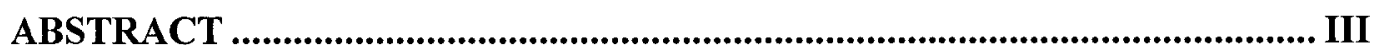

LIST OF TABLES ....................................................................................................... VII

LIST OF FIGURES .........................................................................................VIII

LIST OF APPENDICES........................................................................................

1 INTRODUCTION ....................................................................................

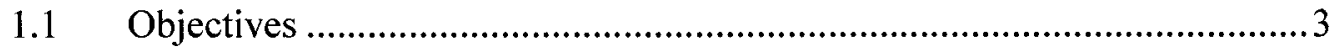

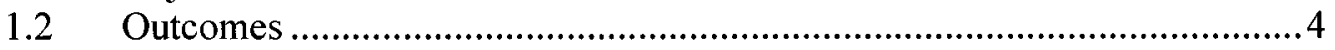

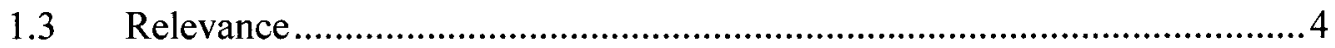

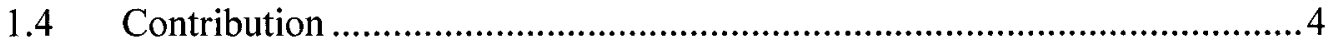

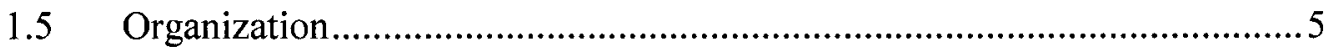

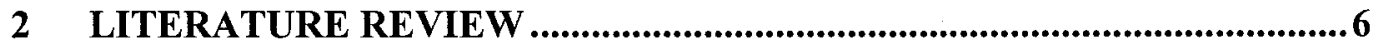

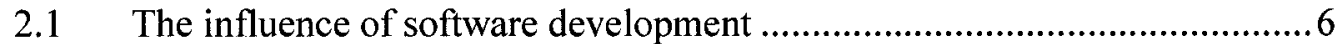

2.2 OSS adoption in software development .................................................. 7

2.2.1 What is Open Source software .................................................... 7

2.2.2 Who is using Open Source software................................................ 7

2.2.3 OSS product categories related to software development environment 8

2.2.4 Why use Open Source in the software development activities ........... 12

2.2.5 Why people fail to consider OSS options or adopt OSS ................... 15

2.2.6 Choosing OSS in software development ...................................... 18

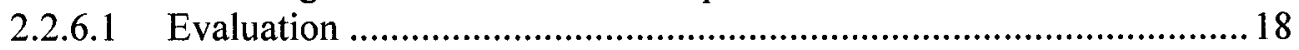

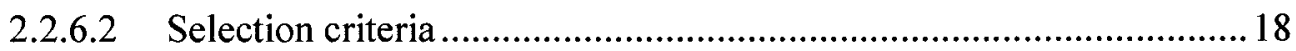

2.2.7 Difference between small and big size companies in OSS adoption ..21

2.3 The pros and cons of OSS adoption comparing to COTS reuse ................22

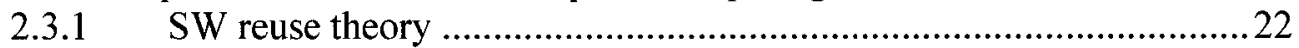

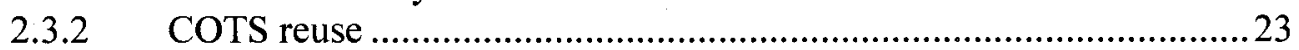

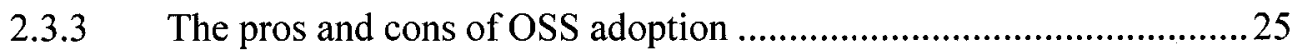

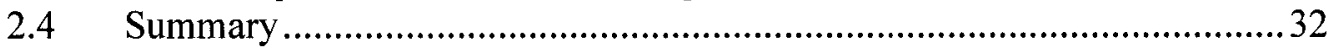

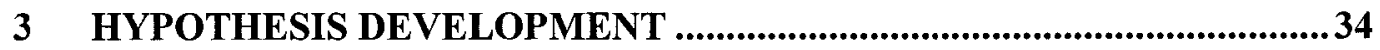

3.1 Degree of OSS adoption (H1 model) ........................................................... 35

3.2 Maturity level of OSS adoption (H2 model)............................................ 37

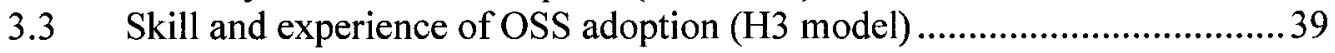

$3.4 \quad$ Selection criteria of OSS (H4 model) ......................................................... 39

3.5 OSS adoption in small and large sized organizations (H5 model)..............40

4 RESEARCH METHOD.............................................................................42

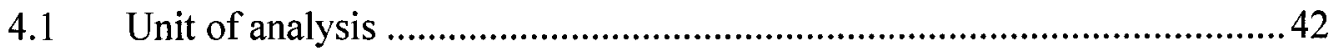

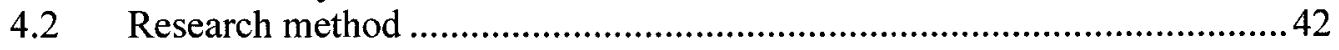

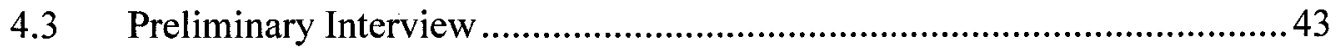

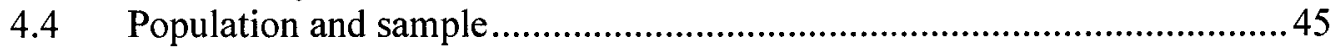

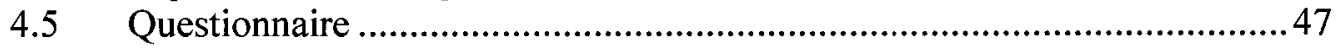

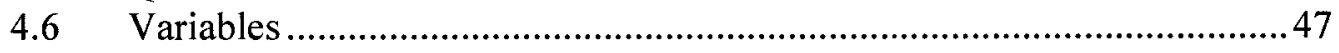

4.6.1 Independent variables ............................................................. 48

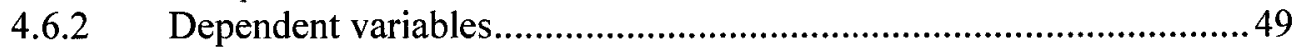

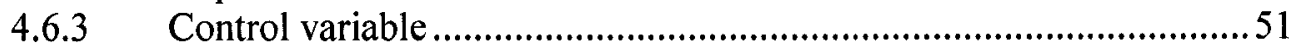




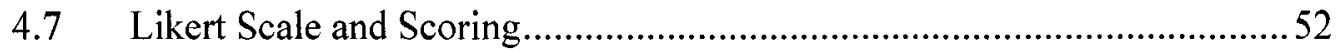

5 RESULTS, ANALYSIS, AND DISCUSSION ...........................................54

$5.1 \quad$ H1 Model: Hypotheses H1 (a, b \& c) ......................................................55

$5.2 \quad \mathrm{H} 2$ Model: Hypotheses H2 (a, b \& c) .....................................................5

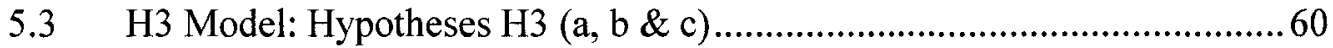

$5.4 \quad$ H1 Mode4: Hypotheses H4 (a, b \& c) ..................................................6 61

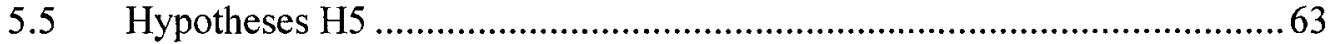

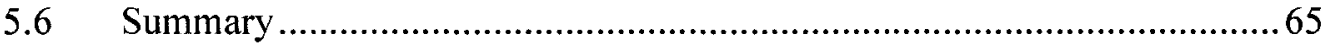

6 CONCLUSIONS, LIMITATIONS, AND FUTURE RESEARCH..............67

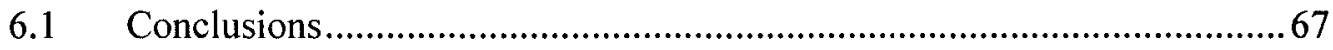

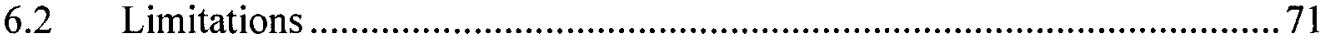

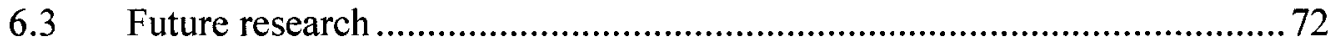

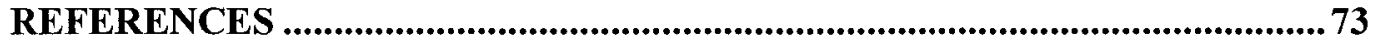

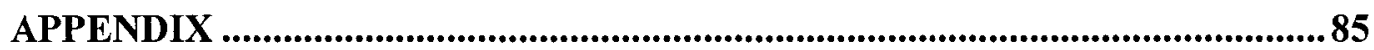




\section{LIST OF TABLES}

Table 1: Open Source software categories related to software development ...............9

Table 2: Popular OSS products related to software development ............................ 11

Table 3: Advantage and disadvantages of commercial components versus custom

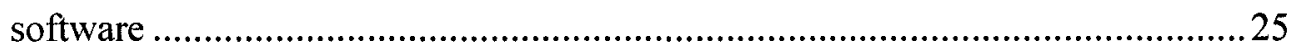

Table 4: Open Source software licenses and their effects.................................... 31

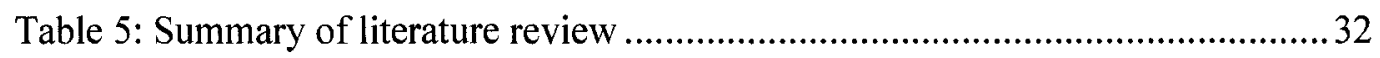

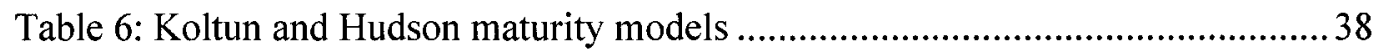

Table 7: Descriptive statistics and correlation coefficients for the study variables ... 55

Table 8: Correlation between the attributes of degree of adoption and cost efficiency, productivity, and product quality ...........................................................55

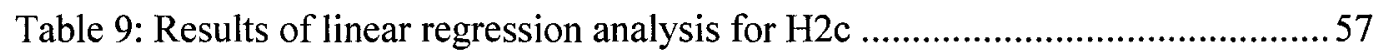

Table 10: Correlation between the attributes of maturity level and cost efficiency,

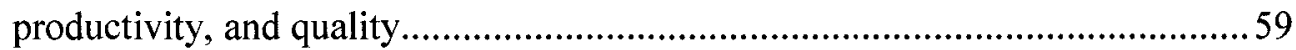

Table 11: Results of linear regression analysis for $\mathrm{H} 2 \mathrm{~b}$ and $\mathrm{H} 2 \mathrm{c}$...........................59

Table 12: Correlations between skill \& experience and development cost efficiency,

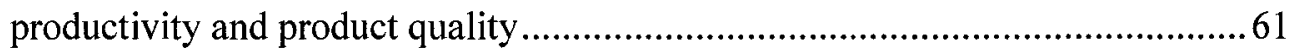

Table 13: Correlations between selection criteria and development cost efficiency, productivity and product quality .........................................................6 62

Table 14: Results of linear regression analysis for $\mathrm{H} 4 \mathrm{a}$ and $\mathrm{H} 4 \mathrm{c} . \ldots \ldots \ldots \ldots \ldots \ldots \ldots \ldots \ldots . . . . . . . . . . . . . . .63$

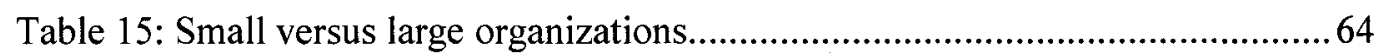

Table 16: Summary of hypothesis Testing.......................................................6 65 


\section{LIST OF FIGURES}

Figure 1: Open Source selection model ............................................................... 21

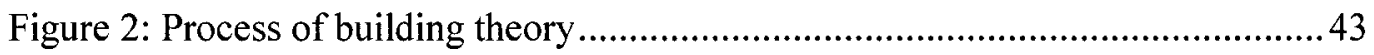

Figure 3: Population and sampling method ....................................................... 45

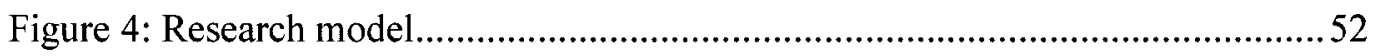

viii 


\section{LIST OF APPENDICES}

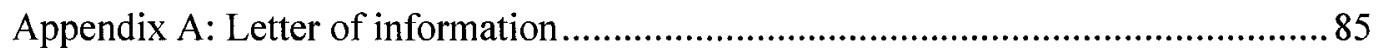

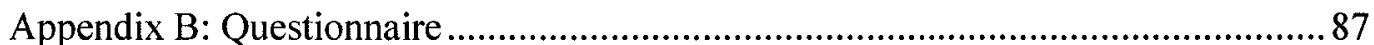




\section{INTRODUCTION}

Open Source Software (OSS) is now a serious force that is shifting the traditional economic paradigm of software development and it is also a big consideration for commercial software development in the formulation of economic strategies. Traditionally, OSS has been successful in the low level infrastructure layer such as the Linux and Apache web server (Macedonia, 2001) (Haber, 2002) (Foley, 2002) (Bokhari, 1995). Over the past ten years, OSS' success has moved up to the middle layer (For example, MySQL, Qmail and Horde) and component-based development and reuse (Fitzgerald, 2004) (Gabriel \& Goldman 2002). Nowadays, OSS' adoption provides more options for software development activities. Because of so many mature software development and management tools, development platforms, and components that are available for people to use freely, OSS adoption can be as simple as using one software package on a single computer, embedding an OSS component into a software product, or in some cases, implementing an entire OSS development management solution to do complex tasks.

As a new option for component-based development, OSS has become an important consideration when managers are making software development strategies. The use of such components in commercial software development is rising (Wang \& Wang, 2001) (Spinellis \& Szyperski, 2004) (Fitzgerald, 2004) (Gabriel \& Goldman 2002). The term 'Open Source' is a combination of two properties - free to access/modify source code and to give (part of) it away (Gacek \& Arief, 2004), (Lewis, 1999), (Norris, 2004), (Thomas \& Hunt, 2004). The importance of this to the software community is the opportunity to use existing software systems as a base for a new 
design. This gives a rich foundation to reusable software components that are generally available at the cost of a mouse click. When reusing OSS, code adoption can happen at the level of fine granularity - few lines of code; at medium level granularity -reusing a class, method, or component; or big granularity -reusing some functionality, a file, or a whole system. This flexibility (availability of source code) removes the artificial adoption boundary imposed by the binary code reuse (Frakes $\&$ Terry, 1996), (Gacek \& Arief, 2004), (Hecker, 1999), (Lawton, 2002). Source code availability allows people to improve, fix, and/or support the reused components (Ajila \& Bailetti, 2006), (Basili, Briand \& Melo, 1996). It is also possible for them to decide on what, how, and where to reuse it. The reuse in general provides the following advantages (Ajila, 2005), (Basili, Briand \& Melo, 1996), (Gaffney \& Durek, 1989), (McArthur, 2002) - reduced time to market, reduced product development costs, improved process predictability, increased product quality, achieved large-scale productivity gains, and increased customer satisfaction.

The reuse of OSS components in commercial software is rising and in many cases a legitimate choice in commercial application (Stone, 2002), (Thomas \& Hunt, 2004), (Voth, 2003), (Wall, 2001), (Mili, H.2003) (Laird, 2002) (Godfrey \& Tu, 2000). Without adjusting appropriate procedures, adopting OSS can be challenging in software development. For example, you might have to do some extra work on legal checks and management.

It is difficult to say categorically how software organizations are benefiting from OSS adoption. Today there is a lot of literature based on case studies (Fitzgerald \& Kenny, 2004), (Hecker, 1999), (Koltun \& Hudson, 1991), (Leavitt, 2001) about Open Source 
contributions (Norris, 2004), (Pearson, H.E. 2000) that show the importance of OSS adoption in software development. But, to the best knowledge of the authors, there is a lack of empirical studies on how OSS adoption affects the software development economics. In addition, there has been some argument either in favor or against the adoption of OSS due to security, economics of scale, licensing, and quality (Gaffney

\& Durek, 1989), (Glass,1999), (Koltun \& Hudson,1991), (Kshetri, 2004), (Lewis, 1999), (Open Source Initiative, 2003), (Scacchi, 2004), (Wang \& Wang 2001). Nearly all of these arguments are based on case studies or experience reports. There is therefore the need to take a critical look at OSS adoption and how it impacts software development economics.

\subsection{Objectives}

This research tries to lay out some of the factors that might need to be addressed in weighing the benefits of software development using OSS components. Therefore, the major objectives of this research are

1. To identify the factors that affect software development;

2. Develop a model that relates these factors and software development parameters when OSS is adopted;

3. Investigate empirically how OSS adoption affects the software development productivity, cost efficiency, and product quality;

4. Determine if there is any difference between small and large sized organizations when adopting OSS. 


\subsection{Outcomes}

The main outcome of this research is get some insights about effects of OSS adoption on software economics in order to help organizations to increase the benefits brought by OSS adoption, and reduce the relevant potential risks.

\subsection{Relevance}

Three groups may be interested in this research. First, top management teams of large companies will be able to use the outcomes of this research to know which factors of OSS adoption are significant for internal changes of software development. This will enable them to design strategy for OSS adoption.

Second, researchers in strategic management may be interested in how to assess the impacts of OSS adoption on software development economics.

Third, OSS community may be interested in the research result so that they will know how to improve OSS product and OSS architecture.

\subsection{Contribution}

This research contributes to the software development literature stream that examines the strategic motivations of OSS adoption. Also managers can use the insights gained from the research to adjust the strategies of OSS adoption in order to improve software development economics. 


\subsection{Organization}

This thesis is organized into six chapters. Chapter 1 is the introduction. Chapter 2 provides a literature review on OSS' definitions, adoption, reuse theories, and the influence on software development. Chapter 3 develops testable hypotheses based on OSS adoption factors and how they affect software development productivity, cost efficiency, and product quality. Chapter 4 describes research methods, variables and the measurements used to test the hypotheses. Chapter 5 discusses the research results. Finally, chapter 6 provides the conclusions which describes the limitations of the research and identifies opportunities for future researches. 


\section{LITERATURE REVIEW}

This chapter is organized into three sections. The first section reviews the influence of software development as a general point of view. The second section reviews the literature on OSS adoption in software development. It explains what OSS is and lists some specific OSS packages/projects relevant to software developments. It also summarizes case studies describing OSS adoption's main advantages and concerns for software development on the perspective of organizations. In addition, it addresses the OSS' evaluation processes and selection criteria which are used normally in many organizations. The last section presents the literature on OSS adoption in software development. It compares OSS adoption as an alternative of component reuse in software development with traditional Commercial Off-The-shelf Software (COTS) reuse.

\subsection{The influence of software development}

According to literature review, Total Cost of Ownership (TCO) of technology and the strategic value are the two main aspects of software development influences (Hickman, 2004).

TCO is the cost of implementers' technology solution for a software development project (Hickman, 2004). It includes the initial cost of acquiring the software (e.g. purchase price and license fees), hardware costs, installation costs (e.g. staff time or consultant costs), end-user training costs, maintenance cost (e.g. annual maintenance fees), support costs, and upgrade costs. 
In the software development context, strategy value means accounting for the mission-based value that a technology might bring to a software development project, which mainly includes impact on software development productivity and the quality of products delivered to the customer (Hickman, 2004).

\subsection{OSS adoption in software development}

\subsubsection{What is Open Source software}

OSS is defined roughly as "programs whose licenses give users the freedom to run the program for any purpose; to study and modify the program and to redistribute copies of either the original or the modified program without having to pay royalties to the previous developers" (Open Source Initiative, 2003).

In contrast, commercial software (also called proprietary software), is software that is distributed under commercial license agreements, usually for a fee, and without access to the source code (Hunt \& Thomas, 2002).

\subsubsection{Who is using Open Source software}

More and more organizations in business and government are turning to Open Source (Franck \& Jungwirth, 2003). Large computer companies like IBM, Sun, and Apple have embraced Open Source as parts of their software strategy. Governments have turned to Open Source both as a way to share software they created and as a way to lower costs. For instance, the City of Munich switched all 14,000 of its computers to 
Linux (Macedonia, 2001) (Haber, 2002) (Foley, 2002) (Bokhari, 1995). The same trend is beginning to happen in relation to server and web applications. The large majority of computers used to run the Internet run Open Source tools, with $65 \%$ of web servers currently running the Apache web server (Netcraft LTD, 2003). The Association for Progressive Communications uses Open Source for a wide variety of applications including its global network of web mirrors used to fight corporate and government censorship around the world. "Seeds of Diversity" uses Open Source database tools to store and manage horticultural data. Oneworld has adopted Open Source content management and online community systems to run its global network of portals (Derick \& West, 2003) (Fitzgerald, 2004) (Gabriel \& Goldman 2002).

These examples are just the tip of the iceberg. Most organizations just download Open Source and use it, not taking the time or effort to tell anyone about it. The numbers of the people and organizations that are using OSS are big and growing (Murrain, 2004) (Gottlieb, 2006).

\subsubsection{OSS product categories related to software development environment}

When people hear the term, Open Source, they immediately think of Linux -the free Open Source operating system that has become popular as a server platform over the past 10 years (Macedonia, 2001) (Haber, 2002) (Foley, 2002) (Bokhari, 1995). However, there is much more to Open Source than just Linux. In fact, there are many distinct OSS categories. Table 1 below lists the OSS categories that are related to software development and the numbers of projects in each field. 


\begin{tabular}{|c|c|c|}
\hline & $\begin{array}{l}\text { The number of } \\
\text { projects }\end{array}$ & Notes \\
\hline Algorithms & 403 & \\
\hline Genetic Algorithms & 56 & \\
\hline Build Tools & 1921 & $\begin{array}{l}\text { Import libraries or data to build applications, } \\
\text { charts, images... }\end{array}$ \\
\hline CASE & 123 & $\begin{array}{l}\text { Computer-based product aimed at supporting one } \\
\text { or more software engineering activities within a } \\
\text { software development process. }\end{array}$ \\
\hline Code Generators & 1984 & \\
\hline Compilers & 1214 & \\
\hline Cross Compilers & 84 & \\
\hline Debuggers & 609 & \\
\hline Design & 283 & $\begin{array}{l}\text { UML modeling tools, model designer, optimize } \\
\text { design, }\end{array}$ \\
\hline Documentation & 261 & $\begin{array}{l}\text { Documentation tools can extract the } \\
\text { documentation from your source code or some } \\
\text { contents into deliverable formats. }\end{array}$ \\
\hline Frameworks & 1986 & Frameworks to help many applications. \\
\hline Internationalization & 120 & \\
\hline Interpreters & 1241 & \\
\hline Localization & 99 & \\
\hline Modeling & 242 & \\
\hline Object Brokering & 422 & \\
\hline CORBA & 98 & \\
\hline Object Oriented & 593 & With some functionality ready to be reused. \\
\hline Profiling & 119 & \\
\hline
\end{tabular}




\begin{tabular}{|l|l|l|}
\hline Quality Assurance & 293 & \\
\hline Testing & 505 & \\
\hline Usability & 107 & Check and review usability of source code. \\
\hline User Interfaces & 820 & \\
\hline Version Control & 594 & \\
\hline Virtual Machines & 162 & \\
\hline
\end{tabular}

(Source: Open Source Development Network Inc., 2003)

A categorized table of the best established Open Source applications that relate to the software development environment is shown below. This table is based on David A. Wheeler's GRAM. 


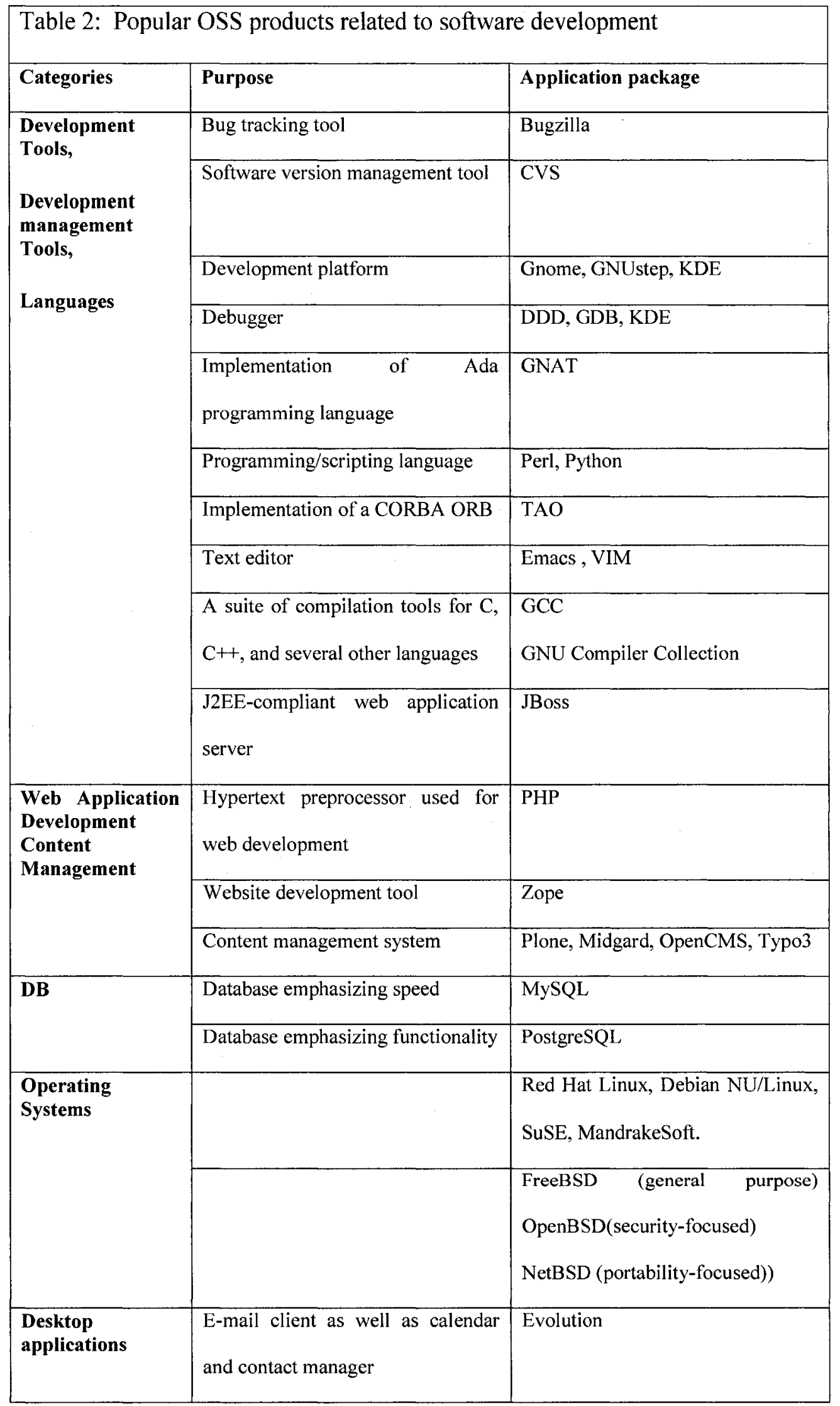




\begin{tabular}{|c|c|c|}
\hline \multirow{6}{*}{$\begin{array}{lr}\text { Graphical } & \text { user } \\
\text { interface } & \text { (GUI) } \\
\text { infrastructure }\end{array}$} & Web browser and e-mail client & Mozilla \\
\hline & $\begin{array}{l}\text { Office suite, including word } \\
\text { processor, spreadsheet, and } \\
\text { presentation software }\end{array}$ & $\begin{array}{l}\text { OpenOffice.org, } \\
\text { Abiword, KOffice }\end{array}$ \\
\hline & Bitmapped image editor & GIMP \\
\hline & Accounting & GnuCash \\
\hline & Desktop environment & GNOME, KDE \\
\hline & $\begin{array}{l}\text { Graphics infrastructure which } \\
\text { implements the X window system }\end{array}$ & XFree86 \\
\hline \multirow[t]{4}{*}{ Security } & Network security scanner & Nessus, Nmap \\
\hline & $\begin{array}{l}\text { Library implementing the SSL and } \\
\text { TLS security protocols }\end{array}$ & OpenSSL \\
\hline & $\begin{array}{l}\text { Secure replacement for telnet, Rcp, } \\
\text { and ftp }\end{array}$ & OpenSSH \\
\hline & Intrusion detection & Snor \\
\hline \multirow[t]{5}{*}{ Network Services } & Web server & Apache \\
\hline & DNS & Bind \\
\hline & Mailing list manager & Mailman \\
\hline & E-mail server & Postfix, Sendmail \\
\hline & Samba & Samba \\
\hline
\end{tabular}

(Source: David A. Wheeler, 2003)

\subsubsection{Why use Open Source in the software development activities}

Although the true cost of software is more than its initial purchase price, the fact that OSS is freely available, freely upgradeable, and along with other characteristics, such as security, stability, access to source code (for customization), and the absence of marketing gimmicks in the software, have led it to its popularity (Derick \& West, 2003). 
The choice of which software to use for a particular application should be driven by some specific needs and circumstances. But there are a number of broad benefits and challenges that are common across the whole realm of Open Source. Understanding these gives the general idea about whether or not Open Source is right for the organization.

There has been a great deal of discussion for the benefits of OSS. Amidst it all, it may seem that OSS is being presented as some sort of cure. Certainly, it is not. Yet, if used with an understanding of its limitations and challenges, OSS does present some clear benefits to many organizations.

\section{Lower information technology costs}

Some commercial products, like simple tools or small applications, have very low software acquisition costs. Other products, like complex databases, financial/fundraising packages, or server operating systems have a higher acquisition cost (Fitzgerald, 2004) (Gabriel \& Goldman 2002). In some cases, nonprofit organizations can get many software packages donated or at reduced costs, which may reduce or eliminate the acquisition cost for the software itself. Sometimes, however, organizations are limited in how many copies of a product will be on reduced price or donated (for example, an organization can only get 50 user licenses of Microsoft Office XP from DiscounTech, so large organization would not be able to take full advantage of this donation (Derick \& West, 2003).) However, virtually all OSS are available for no acquisition cost whatsoever, and no multiple licenses are needed. 
Open source eliminates the need to pay for software licenses (Lerner \& Tirole, 2002) (Bonaccorsi \& Rossi, 2005). Of course, this does not mean that you can eliminate IT costs altogether. There is still a need for staff and equipment to make it all work. But Open Source can definitely lower some costs, especially for organizations which need advanced servers, databases and web applications. The administrative costs are also cut by OSS' adoption when compared to the costs for the tasks and delays to get internal approval for using commercial off-the-shelf (COTS) products. The arrangements for a purchase order, authorization seek, or other financial bureaucracies can be avoided by using OSS (Fitzgerald, 2004) (Laird, 2002).

\section{Many OSS sophisticated development platform/tools and management tools} available for free or with very low cost.

Although more proprietary software development packages are available, there are so many Open Source packages that most users can find an application that meets their needs exactly (Wu \& Lin, 2001). Tables 1 and 2 show the broad availability. Today, even small programming shops with only a couple of developers can use the sophisticated tools that once only large and well funded development efforts could afford. Many OSS development platforms/tools and management tools can help to improve software engineering processes, such as version control, bug tracking, release engineering, and regression testing(Spinellis \& Szyperski, 2004). These processes are standard in any organizations which have Capability Maturity Model for Software (CMM) Level 3 or above; but used to be ignored by most small shops (Spinellis \& Szyperski 2004).

\section{Flexible software solutions}


The fact that the code is "open" means that software can be modified to respond to needs not addressed by the original developer. The most obvious benefit of this responsiveness is the ability to translate software into local languages (Franck \& Jungwirth, 2003).

\section{Better security}

Mature Open Source applications, such as Linux, Apache, SendMail, OpenOffice.org, tend to be more secure than their proprietary counterparts. This is partly due to the fact that the code is open, allowing system administrators and others concerned with the security to quickly identify problems and propose solutions. Also, Open Source applications tend not to be targeted by people who purposely make viruses (Franke $\&$ Hippel, 2003) (Lakhani,., Wolf, Bates \& Dibona, C. 2002) (Ortiz, \& Jr, 2001).

\subsubsection{Why people fail to consider OSS options or adopt OSS}

\section{Efforts on market}

OSS is a relatively new concept for many acquirers, and as a result, some acquirers inadvertently fail to consider OSS options. Software acquirers are usually unaware of available options, since OSS projects are not generally advertise and they often do not respond to the government Request for Proposals (RFPs). In addition, OSS distribution processes do not fight for market share; so even widely-used programs can first appear to be less common. But proprietary software vendors spend considerable resources on marketing their software (David \& Wheeler, 2004).

\section{Experience}


Compared to commercial software, OSS is still a new thing. Most of the acquisition organizations don't have as rich experience in acquiring OSS as they do proprietary software (David \& Wheeler, 2004).

\section{The indirect costs outweigh the benefits}

The elimination of license fees is a significant cost saving. However, many people get caught thinking that using Open Source will be totally without costs. It is important to consider all costs including training and support. There are still some costs with OSS adoption, specifically around configuration and support. One needs to consider all the TCO and Return on Investment (ROI) factors. Using OSS may actually increase financial business risks because "most of the software development's cost lies in the maintenance or post release phase" (Lewis, 1999). Thus, open source tools can sometimes be more expensive in these areas (Fitzgerald, 2004) (Gabriel \& Goldman 2002).

Making an organization-wide switch from proprietary software can be costly (Fitzgerald, 2004) (Gabriel \& Goldman 2002). Microsoft, for instance, provided the relevant information from an independent, non-sponsored study performed by the Yankee Group of 1000 IT administrators and executives. By using the Linux, UNIX and Windows' TCO comparison, arguments against the free aspect of OSS are provided. For instance, "all of the major Linux vendors and distributors have begun charging "hefty premiums" for "must-have items". "In large enterprises, a significant Linux deployment or total switch from Windows to Linux would be three to four times more expensive -and take three times as long to deploy- as an upgrade from one version of the Windows to an newer release" (Microsoft Corporation, 2004) (Ballmer, 
2004).Also using Linux in a real-time embedded environment needs not only time for your own learning curve to make it suitable and integrate it but also extensions that will require subsequent maintenance effort. (Ruffin,2004).

Sometimes, compatibility issues with Mission-Critical Applications can make OSS adoption cost more than what was planned at the beginning of the project. In particular, when considering using Linux as an operating system, one need be aware that many software vendors, especially smaller ones, still do not support versions that can run on Linux. This is especially true of "niche" software products for the nonprofit sector, such as case tracking programs for legal-service organizations, or mortgage-tracking programs used by affordable- housing groups (Ballmer, 2004). Organizations that depend heavily on one of these programs find that, if they want to use Linux, they must also maintain a Windows machine dedicated to running that mission-critical program (Ballmer, 2004). If that is likely to be the situation, the costs of maintaining the additional node must be included in the TCO. In addition, any inconvenience to users could be considered a drain on strategic value.

\section{Cost reduction alone is not big concern}

No matter what the commonly spread arguments about the cost reduction is, the big advantage of using OSS, for some companies, would not be the cost (Derrick, 2003). For instance, from the theory of innovation and standard adoption proceeding, "only three of the ten companies stated that the cost of software was a significant factor in their decision in adopting Linux" (Derrick, 2003). From the research environment "Some users even claim to be indifferent to software costs, because they pass the amounts to their research grants" (Laird, 2002). 


\subsubsection{Choosing OSS in software development}

\subsubsection{Evaluation}

The processes for evaluating OSS and proprietary software are the same in a broad way, but they are necessarily different in detail. For example, it is generally not possible to examine the source code or developmental discussions of the proprietary software without special arrangements, while that's possible when using OSS (Murrain, 2004) (Gottlieb, 2006).

Software companies have far more experience in acquiring proprietary software because proprietary software vendors spend considerable resources on marketing their software (Murrain, 2004) (Gottlieb, 2006). In the case of OSS, there is no standardslike group being created to maintain GRAM also known as GRAS lists. Some groups have created preliminary lists, but they are very limited.

\subsubsection{Selection criteria}

As a strategy in software development management, the selection criteria of OSS must be set to meet the criteria of the software projects/program (Gottlieb, 2006). The choice should be driven by some specific needs and circumstances. These include support, mature functionality, security, quality, or cost etc. (Murrain, 2004), (Gottlieb, 2006).

Whether you are working with Open Source or commercial tools, picking the right software can be a difficult process. Often, people don't discover that they have made a wrong software choice until it is too late. Also, it is easy to be swayed by an attractive new feature or compelling promotional language on a web site, even if the software 
itself has certain deficiencies. The best way to avoid these pitfalls is to invest in a thorough and thoughtful review process (selection criteria) before choosing a new piece of software (Murrain, 2004), (Gottlieb, 2006).

The selection criteria can be categorized as organizational needs and technical issues based on David Wheeler's three steps approach (Wheeler, 2006). Once people have completed the three steps, they should have a score for each of the software packages. This score should be a good indicator of which package is best for them. If a package scores very low, it is likely that it will cause problems once implemented (Wheeler, 2006). The basic main three steps are:

\section{Step One: Define your needs and constraints}

The first step of the process is to clearly define your needs and constraints with priorities. This should include both the overall needs of your organization, like the budget, timeframe, skills and needs of individual users, such as language, compatibility or technical reasons. All of these factors will play a major role in the process of identifying your software options and making a final software selection.

\section{Step Two: Identify your options}

The next step in the process is to come up with a short list of three to five software packages that are likely to meet your needs. This is basically a process of reading through information about various software packages and comparing them against the needs and constraints that you listed in step 1.

\section{Step Three: Undertake a detailed review}


The final step is about reviewing and choosing a software package from your short list. At this stage, all of the packages that you are reviewing should be generally suitable for your task. The aim of this section is to assess which possible options will be best for the organization. This assessment can be done by rating each package against the criteria (Wheeler, 2006).

In terms of ranking, each software package on the short list should be rated against each of the criteria above. A score from one (insufficient) to five (excellent) should be given for each criterion.

Note that if OSS meets most, but not all the required needs, the OSS should still be considered. One of the hallmarks of the OSS is flexibility; OSS can be customized to meet a particular need if necessary. If an OSS doesn't have all the needs but many of them, an acquirer should examine the pros and cons of modifying the software to meet his or her needs. Typically, such changes are performed by working with the existing project developers, so that the support costs of these software can be transitioned away from an individual acquirer (Wheeler, 2006).

According to the model of the stages involved in locating and using an Open Source component, developed by Madanmohan and De, the OSS adoption process is a cyclic process involving three related activities: collection, incubation, and critical revision (Madanmohan and De, 2004). As illustrated in Figure 1, developers do not visit these stages on a linear path, and they might return to earlier phases and iterate often. 
Figure 1: Open Source selection model

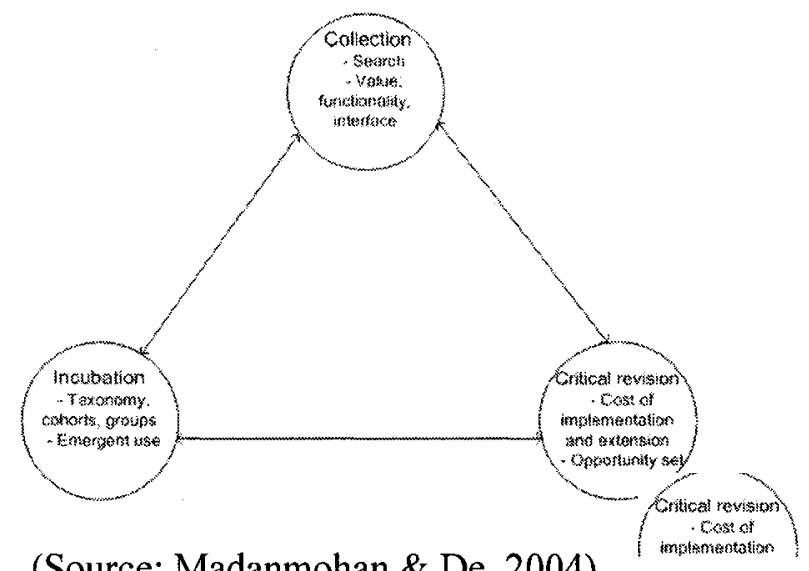

(Source: Madanmohan \& De, 2004).

\subsubsection{Difference between small and big size companies in OSS adoption}

To adopt OSS, most big companies must consider if they have equivalent commercial grade technical support available at a reasonable cost (Wang, 2001). This includes training, documentation, real time support, bug fixes, and professional consulting if needed. To enable the development team to get off to a quick and smooth start, having the binary distribution and wide availability of the OSS are preferable so that the initial familiarization process can occur seamlessly. However, small firms rarely have the resources to pay for integration or maintenance services from the likes of IBM or HP, and are more likely to rely on their own skills and free online support available from Open Source communities. It is probably not surprising that vendor support is more important to larger organizations with financial means to buy technology and support contracts from major IT vendors. Three very large companies (FastFood, Biotech, and Semico), cited vendor support as being important factor that would make them more comfortable with OSS adoption (Ruffin, 2004). 
Quoting the NASA project OSS adoption experience, "When we contacted Open Source developers about a problem in their component, they responded immediately with workaround suggestions and kept us informed as they worked to correct the issue. In one case, they diagnosed the problem, fixed it, and then released a corrected version in less than a day. When we encountered a problem in a commercial component, we often had difficulty even getting in contact with the developers. It soon became clear that the most we could do was hope for the problem to be fixed in the commercial product's next release, which was often months away (Norris, 2004)." Furthermore, many software based products require long term support for each system or software release, especially embedded software (Ruffin, 2004).

\subsection{The pros and cons of OSS adoption comparing to COTS reuse}

\subsubsection{SW reuse theory}

Software reuse is the process whereby software systems are created from an existing software rather than building them up from scratch. Requirements, algorithms, functions, business rules, architecture, source code, test cases, input data, and scripts can all be reused. Reuse offers the potential to lower the cost of the development, shorten time to market, and in most cases better quality (Ajila, 2005), (Basili, Briand \& Melo, 1996), (Crnkovic \& Larsson, 2002) (Mili, H.2003)( Laird, 2002) (Godfrey \& Tu, 2000). Architecture reuse can be the primary means for achieving the cost savings potential of code reuse. Some traditional types of reuse include Black-Box Reuse, Component-adaptive Grey-Box Reuse, and White-Box Reuse. For example, Black-Box Reuse may reuse the retrieved components "as is", and Componentadaptive Grey-Box Reuse may reuse the retrieved components after interface-level 
modifications of the components. The term White-Box reuse is employed when a component is reused to drive a new desired component either through inheritance or delegation (Lattanzi \& Henry, 1998), (Prieto-Diaz, 1993).

Reuse is a powerful technique, because it allows functionality to be provided rapidly to the user (Gaffney and Durek, 1989). To exploit reuse, the development team must recognize the realities of reused products (Basili, Briand and Melo, 1996). First, the product being reused must closely match the need that it is trying to solve. Second, the reused product should be well documented. Third, it should have been designed for a similar scenario to that for which it is going to be used. Fourth, the reuse product should be stable. Above all, the key to successful reuse is determining the components and functions that are needed before forcing a decision to reuse products.

Reuse can sometimes be a significant constraint on software either by slowing it down or by making the overall design of the system clumsy and/or unstable. It can increase the long-term cost of the system (Basili, Briand \& Melo, 1996), (Gaffney \& Durek, 1989), (McArthur, 2002). The distinguishing characteristic between these two scenarios is whether reuse was appropriate. Reuse is not a silver bullet. Rather, it is a powerful tool that can help significantly when used correctly (Banker and Kauffman, 1991) (SPMN, 2003).

\subsubsection{COTS reuse}

Reuse of commercially available software has some unique disadvantages. Commercial entities are motivated to limit a user's ability to change products. This is often accomplished by including and then recommending the use of some proprietary 
features (Royce, 1998). In addition, the update cycle for a commercial package can be a significant drain on maintenance resources. The costs of keeping current product and integrating new product releases should be assessed as a part of overall life cycle costs (Poulin, 1997).

The use of off-the-shelf products is certainly a common approach which is for software human-generated source code size reduction (Poulin, 1997) (Royce, 1998). . The reuse decision has a significant impact on a project's overall architecture and must be made early in the life cycle as part of the architecture design (Poulin, 1997) (Royce, 1998). Table 3 identifies some of the advantages and disadvantages of using commercial components. These trades-offs have happened more frequently on the effects of quality, cost, supportability, customizability, extensibility, availability, integrate-ability, and security. 


\begin{tabular}{|c|c|c|}
\hline APPROACH & ADVANTAGES & DISADVANTAGES \\
\hline $\begin{array}{l}\text { Commercial } \\
\text { Components }\end{array}$ & $\begin{array}{l}\text { Predictable license } \\
\text { costs } \\
\text { Broadly used, } \\
\text { mature technology } \\
\text { Available now } \\
\text { Dedicated support } \\
\text { origination } \\
\text { Hardware/software } \\
\text { independence } \\
\text { Rich } \\
\text { functionality in }\end{array}$ & $\begin{array}{l}\text { Up-front license fees } \\
\text { Often inadequate reliability and stability } \\
\text { Unnecessary features that consume extra resources } \\
\text { Frequent upgrades } \\
\text { Recurring maintenance fees } \\
\text { Dependency on vendor } \\
\text { Run-time efficiency sacrifices } \\
\text { Functionality constraints } \\
\text { Integration not always trivial } \\
\text { No control over upgrades and maintenance } \\
\text { Multiple-vendor incompatibilities }\end{array}$ \\
\hline $\begin{array}{l}\text { Custom } \\
\text { Development }\end{array}$ & 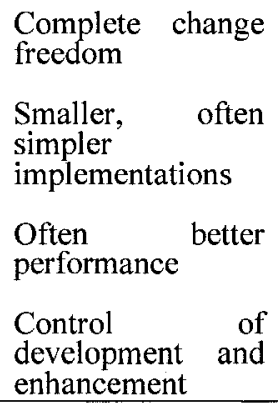 & $\begin{array}{l}\text { Expensive, unpredictable development } \\
\text { Unpredictable availability date } \\
\text { Undefined maintenance model } \\
\text { Often immature and fragile } \\
\text { Simple-platform dependency } \\
\text { Drain on expert resources }\end{array}$ \\
\hline
\end{tabular}

(Source: Royce, 1998)

\subsubsection{The pros and cons of OSS adoption}

As an alternative for component-based development, OSS has become an important consideration when managers are making the software development strategy. Many OSS adoption literature shows that, in some aspects, OSS components are the same as commercial off-the-shelf (COTS) software. Project developers acquire components and use them "as is", or with minor modifications, which can really improve the developers' productivity (Applewhite, 2003, Madanmohan and De, 2004; Fitzgerald and Kenny, 2004; Hecker, 1999; Ruffin and Ebert, 2004; Spinellis, Szyperski, 2004), 
but they are necessarily different in detail. In this section, some pros and cons are lists below.

\section{Peer review}

From the peer-review point of view, "the adopted Open Source code will typically be of higher quality than the custom-developed code's first incarnation" (Spinellis, 2004) (Mili, H.2003)( Laird, 2002) (Godfrey \& Tu, 2000). Peer review is an important factor in OSS development because if provides the necessary connection of attention and brain power of entire software communities to OSS evaluation (Raymond, 1998) (Lewis, 1999). OSS is, at all stages of its development, examined critically by large numbers of independent expert programmers. In contrast, the proprietary software is usually produced by a limited team with tight deadlines and under great pressure. In the mission-critical projects, NASA's project, it is clearly indicated that OSS adoption positively affects the quality of SW (Norris, 2004). Open Source components that NASA selected includes detailed unit and component level tests that either met or exceeded the testing level in most of the other systems. Therefore, they believe that introducing Open Source into a system has improved the application's overall stability (Norris, 2004). Some arguments also show that adopting OSS can lead to faster development times and less overhead. (Wu, 2001) (Pearson, 2000)

\section{Involvements of Customer}

An additional factor for OSS adoption addressed in many OSS adoption case studies is having customers highly involved in the software development process for better quality (Mili, H.2003)( Laird, 2002) (Godfrey \& Tu, 2000). "Open Source developers are also a subset of the Open Source user community, that is, all Open 
Source developers are users" (Gazec, 2004). The advantages of having users so closely involved in the development process is that they perform an excellent job in developing software with less bugs preventing the need for further attempt to debug the code.

\section{Life cycle}

The reduced cycle time for updates and correction creates a positive cyclic effect as it encourages OSS developers to submit proposals as they discover and fixed a problem (Ruffin, 2004) as opposed to the feeling that commercial components' life cycle was so long and people are less motivated to take the extra time to submit bug reports (Norris, 2004).

\section{Customizability and extensibility}

OSS' source code availability, opposed to commercial software, offers the possibility to integrate software in widely different technical environments and at different levels of code adoptions, such as a few lines of code, a method, a class, a library, a component, a tool, or even a complete system (Spinellis, 2004)(Laird, 2004)(West 2003)(Royce, 1998). However, OSS' customization has its implications depending on the type of license (Lerner \& Tirole, 2002) (Bonaccorsi \& Rossi, 2005). One may need to explicitly permit distribution of software built from a modified source code. The licensing may require derived works to carry a different name or version number from the original software (Open Source Initiative, 2003).

\section{Quality assurance for OSS}


An additional problem related to the OSS source code recycle is the lack of standard processes and metrics to assure the quality of the OSS (Laird, 2004) (West 2003) (Royce, 1998). The quality could vary from the worst code even to an excellent industrial software meeting all the requirement features. This issue may cause organization not to adopt OSS because the code did not meet standard requirements (Spinellis 2004) (Mili, H.2003)( Laird, 2002) (Godfrey \& Tu, 2000).

\section{The Importance of OSS selection criteria}

OSS's widespread availability and the numerous adoption patterns afforded by Open Source are reducing the focus that many organizations put on centrally organized, promoted, and maintained software reuse efforts. But the ability to download OSS from the Internet isn't always a proper substitute for an in-house reusable component library. Adopting Open Source development practices can make organizations pay less attention to strategic planning, detailed requirements elicitation, testing, and organized support as the OSS selection criteria (Spinellis \& Szyperski, 2004). Therefore, to set OSS selection criteria becomes important for organizations in order to get benefits from OSS adoption. Systematically qualifying OSS components should be done before integrating them (Spinellis \& Szyperski, 2004). The selection criteria include industry standard, community support and project maturity (Ruffin, 2004).

For large and complex information technology (IT) projects, all the components must adhere to a particular open standard or protocol (Mili, H.2003) (Laird, 2002) (Godfrey $\& \mathrm{Tu}, 2000)$. It is insufficient that the OSS adheres solely to various open standards. It must also have continuous development momentum to adhere to future revisions of the standards as they evolve (Ruffin, 2004).To choose an OSS, it is important to see if 
it has a strong broad support for distribution and evolution (Ruffin, 2004).

\section{Legal check, organization design and budget control}

Packaging companies serve as intermediaries between the OSS community and the software companies which simply want a certain component for its products (Laird, 2004) (West 2003) (Royce, 1998). In the absence of packaging companies, there is the need to identify the OSS experts in the company who have the commercial, legal, and technical experience to handle day to day engineering and customer questions. For instance, with proprietary software, customers can influence their suppliers' development roadmap to meet specific needs. This is not directly possible with OSS, especially if a user wants to stay aligned with a standard. However, users might be able to create and shape user groups or interest groups to implement a standard (Ruffin, 2004). Furthermore, if the Open Source software is not evolving, or is evolving in a direction inconsistent with the needs of the organization that uses it, the organization must contribute resources to its improvement. These resources can't always be planned in advance because the organization reusing the code typically has limited control over the reused code's development process. Disagreements with or within the software's development team often create product forks and can result in an effort duplication, waste, and confusion in the community depending on the project (Spinellis \& Szyperski, 2004). Forks can also occur owing to genuine irreconcilable technical considerations, in which case they might create different evolutionary paths that are all valuable to their separate user communities (Spinellis \& Szyperski, 2004).

\section{Legal check and management}

Although people understand liability and intellectual property rights fairly well, the implications of OSS related legal and managerial issues are new to many of software 
development top managers. Legal aspects can vary greatly from one piece of OSS to another depending on the license scheme used (Wang \& Wang, 2001) (Lerner \& Tirole, 2002) (Bonaccorsi \& Rossi, 2005). OSS products have several different types of licenses, each of which imposes a different set of restrictions that could potentially impede critical project capabilities such as internal reuse, proprietary custom extensions, and resale. The Open Source Initiative (Open Source Initiative, 2005) has certified 58 licenses as open source licenses as of July 2006. Lerner and Tirole ((Lerner \& Tirole, 2002) categorize open source licenses into three groups according to the restrictiveness of the license: unrestrictive (e.g., BSD), restrictive (e.g., LGPL), and highly restrictive (e.g., GPL). Table 4 lists the following common types of OS license. GPL (GNU Public License) perhaps is the most common one. LGPL (Library GPL), a modified version of GPL applies specifically to software libraries. BSD (Berkeley Software Development) applies mostly on the derivatives and variants of BSD Unix. CPL (Community Public License) is a type of license typically found in community versions of commercial software (Wang \& Wang, 2001) (Lerner \& Tirole, 2002)(Bonaccorsi \& Rossi, 2005). The licensing terms of the chosen software will affect the project scope, such as internal use versus resale. So when OSS is adopted, it always needs to be carefully checked for existing contracts or license schemes within specific constraints. Before any product development, an OSS expert must check for legal clearances of all the external software that will be embedded in a product. 


\begin{tabular}{|c|c|c|c|c|}
\hline $\begin{array}{l}\text { Open Source } \\
\text { Software } \\
\text { Licenses and } \\
\text { Their Effects }\end{array}$ & $\begin{array}{l}\text { Can be mixed } \\
\text { with non free } \\
\text { SW }\end{array}$ & $\begin{array}{l}\text { Proprietary } \\
\text { modifications } \\
\text { can be made } \\
\text { private }\end{array}$ & $\begin{array}{l}\text { Can be re- } \\
\text { licensed }\end{array}$ & $\begin{array}{l}\text { Allows } \\
\text { proprietary } \\
\text { licensing }\end{array}$ \\
\hline $\begin{array}{l}\text { GNU Public } \\
\text { License }\end{array}$ & $\mathrm{Y}$ & $\mathrm{N}$ & $\mathrm{N}$ & $\mathrm{N}$ \\
\hline Library GPL & $\mathrm{Y}$ & $\bar{Y}$ & $\mathrm{~N}$ & $\mathrm{~N}$ \\
\hline $\begin{array}{l}\text { Berkeley } \\
\text { software } \\
\text { Develonment }\end{array}$ & $\mathrm{Y}$ & $\mathrm{Y}$ & $\mathrm{N}$ & $\mathrm{N}$ \\
\hline $\begin{array}{l}\text { Community } \\
\text { Public License }\end{array}$ & $Y$ & $\mathrm{Y}$ & $\mathrm{N}$ & $\mathrm{N}$ \\
\hline Commercial & $\mathrm{Y}$ & $\mathrm{Y}$ & $\mathrm{N}$ & $\mathrm{N}$ \\
\hline
\end{tabular}

(Source: Wang \& Wang, 2001)

To reduce the risks of legal exposure during deployment, license check OSS section criteria must be set up before choosing OSS in order to have a clear, indisputable legal status regarding Intellectual Property Rights (IPR) and the right to use it. For example, the license must not place restrictions on other software that is distributed along with the licensed software. The license must not insist that all other software distributed on the same medium must be open-source software.

Besides, one can distribute proprietary code with the General Public License (GPL) code (even on the same media), but one must package the code separately to avoid the GPL contamination effect. If you have not packaged it separately, proprietary code has to become of the GPL. You must know how to handle packaging with GPL before deciding about using GPL software so that you can choose how to distribute your products. With most licensing schemes, you must distribute all copyrights from all contributors with the software (Wang \& Wang, 2001). 


\subsection{Summary}

The literature review is on four main categories, OSS in general, OSS adoption, COTS reuse and software development economics. Table 5 shows the brief summary of literature review.

\begin{tabular}{|c|c|c|c|c|}
\hline Streams & Factors/Dimensions & Papers & & \\
\hline $\begin{array}{l}\text { Open source } \\
\text { software }\end{array}$ & $\begin{array}{l}\text { OSS definition } \\
\text { OSS product categories relate } \\
\text { to SW development } \\
\text { OSS support, licenses, quality, } \\
\text { security... }\end{array}$ & $\begin{array}{l}\text { Applewhite, } 2003 \\
\text { Bokhari, } 1995 \\
\text { Bonaccorsi \& Rossie, } 2003 \\
\text { Bonaccorsi \& Rossie, } 2005 \\
\text { Franck \& Jungwirth, } 2003 \\
\text { Franke \& Hippel, } 2003 \\
\text { Foley, } 2002 \\
\text { Gabriel \& Goldman, } 2002\end{array}$ & \begin{tabular}{|l|} 
Gacek \& Arief, 2004 \\
Haber, 2002 \\
Laird, 2002 \\
Lawton, 2002 \\
Lerner \& Tirole, 2002 \\
Lewis, 1999 \\
Macedonia, 2001 \\
Norris, 2004
\end{tabular} & $\begin{array}{l}\text { Thomas \& Hunt, } \\
2004 \\
\text { West, 2003 } \\
\text { Wilson, } 1999 \\
\text { Witten \& } \\
\text { Landwehr, 2001 } \\
\text { Wu \& Lin, 2001 }\end{array}$ \\
\hline $\begin{array}{l}\text { OSS } \\
\text { adoption }\end{array}$ & $\begin{array}{l}\text { Motives of firms to adopt OSS } \\
\text { in SW development } \\
\text { Who is doing OSS adoption } \\
\text { How to choose OSS } \\
\text { Risks of adopt OSS } \\
\text { Difference between big and } \\
\text { small companies }\end{array}$ & $\begin{array}{l}\text { Dedrick \& West, } 2003 \\
\text { El Emam, 2001 } \\
\text { El Emam, } 2005 \\
\text { Fitzgerald, } 2004 \\
\text { Fitzgerald \& Kenny, } 2004 \\
\text { Gabriel \& Goldman } 2002 \\
\text { Godfrey \& Tu, } 2000 \\
\text { Gottlieb, } 2006 \\
\text { Hecker, } 1999 \\
\text { Koltun \& Hudson,1991 } \\
\text { Kshetri, } 2004\end{array}$ & $\begin{array}{l}\text { Laird, 2002 } \\
\text { Leavitt, } 2001 \\
\text { Lussier, 2004 } \\
\text { Norris, 2004 } \\
\text { Open Source } \\
\text { Initiative, 2003 } \\
\text { Pearson, 2000 } \\
\text { Ruffin \& Ebert, 2004 } \\
\text { Spinellis \& Szyperski, } \\
2004 \\
\text { Stone, 2002 }\end{array}$ & $\begin{array}{l}\text { Scacchi, } 2004 \\
\text { Thomas \& Hunt, } \\
2004 \\
\text { Voth, } 2003 \\
\text { Wall, } 2001 \\
\text { Mili, 2003 } \\
\text { Wang \& Wang, } \\
2001 \\
\text { Voth, 2003 } \\
\text { Wang \& Wang, } \\
2001\end{array}$ \\
\hline $\begin{array}{l}\text { Software } \\
\text { component } \\
\text { reuse }\end{array}$ & $\begin{array}{l}\text { Motives with reusing COTS } \\
\text { products } \\
\text { Issues with reusing COTS } \\
\text { products } \\
\text { Reuse metrics and models } \\
\text { Reuse Maturity model }\end{array}$ & \begin{tabular}{|l|} 
Ajila, 2005 \\
Ajila, 2006 \\
Basili \& Melo, 1996 \\
Banker \& Kauffman, 1991 \\
Crnkovic \& Larsson, 2002 \\
Devanbu \& Karstu, 1996 \\
Frakes \& Terry, 1995 \\
Frakes \& Terry, 1996 Gacek \\
\& Arief, 2004 \\
Gaffney \& Durek, 1989 \\
Gu, 2004 \\
Koltun \& Hudson, 1991
\end{tabular} & $\begin{array}{l}\text { Hall, } 1999 \\
\text { Hecker, } 1999 \\
\text { Lawton, } 2002 \\
\text { McArthur, } 2002 \\
\text { Ortiz, 2001 } \\
\text { Prieto-Diaz, } 1993 \\
\text { Rothenberger \& Hershaue } \\
\text { Royce, 1998 } \\
\text { Stone, 2002 } \\
\text { Thomas \& Hunt, } 2004\end{array}$ & er, 1998 \\
\hline
\end{tabular}




\begin{tabular}{|l|l|l|l|}
\hline Software & $\begin{array}{l}\text { Influence of software } \\
\text { development } \\
\text { development } \\
\text { Sw development economics } \\
\text { parameters: Cost, productivity } \\
\text { and product quality }\end{array}$ & $\begin{array}{l}\text { Ajila \& Bailetti, 2006 } \\
\text { economics \& Razvan, 2007 }\end{array}$ & Ahire \& Golhar, 1996 \\
& Boehm, 1981 & Kan, 2003 \\
& Poulin, 1997 \\
& Prente \& Dunsmore, 1986 & Richardsonan, 1997 \\
& Frakes \& Terry, 1996 & Royce, 1998 \\
& Fichman \& Kemerer, 1997 & Spinellis \& Raptis, 2000 \\
\hline
\end{tabular}




\section{HYPOTHESIS DEVELOPMENT}

The efforts put into open source development, the success stories, the sound economics, the business opportunities, and the flexible license of open source software are arousing a lot of interest in the software development communities both commercial outlets and governments (Dedrick \& West, 2003), (Lussier, 2004), (Norris, 2004), (Ruffin \& Ebert, 2004), (Voth, 2003). For instance a number of governments around the world have established policies to adopt OSS and in some cases consideration must first be given to OSS adoption before commercially available software is considered. Governments such as China, Norway, India, Portugal, and Israel have rules and regulations for the adoption of OSS. Some states in the US have laws and policies for adopting OSS (Applewhite, 2003), (Voth, 2003), (Wang \& Wang 2001). Large successful OSS projects such as Linux and Apache have been issue of research revealing and pointers to the quality of OSS. In addition, continued increase contributions from the widely diverse community of enthusiasts and users capable of good programming have aided open source development to be a reliable source of software for adoption. Peer review proven success has provided OSS supporters the advantages with enough arguments to claim that "the quality and reliability of open source software is greater than that of commercial software because the code is 'walked through' by more people" (Lerner \& Tirole, 2002). And even, have the courage to support the evidence that - "Perl, Sendmail, and Apache have shown significantly more stability than their proprietary counterparts" (Witten, Landwehr, \& Caloyannides, 2001) (Wu \& Lin, 2001). On the other hand, Wang et al. posits that "OSS packages make actual adoption a real challenge" (Wang \& Wang 2001) and suggests a number of steps to take while adopting OSS. These include availability of technical support, customization, functional upgrade, high reliability, 
backward and standard compatibility, possibility of integration with commercial products, and availability of commercial substitute.

\subsection{Degree of OSS adoption (H1 model)}

Software reuse offers the potential for lower cost of development, short time to market and in most of case better quality (Ajila, 2005), (Basili, Briand \& Melo, 1996), (Crnkovic \& Larsson, 2002). From our initial study, requirements, algorithms, functions, business rules, architecture, source code, test cases, input data, and scripts can all be reused. However, reuse can sometimes be a significant constraint on a software either by slowing it down or by making the overall design of the system clumsy and unstable. It can increase the long-term cost of the system (Basili, \& Melo, 1996), (Gaffney \& Durek, 1989), (Madanmohan \& De, 2004). To take advantage of reuse, the development team must be aware of the realities of reused products (Ajila, 2005), (Basili, Briand \& Melo, 1996). First, the product being reused must closely match the need elicited from the new requirement. Second, the reused product should have a well structured document. Third, the reused product should have been designed for a comparable scenario for what is going to be reused. In general, the reused products must be stable and the components and functions that are needed are determined before forcing a decision to reuse any product (Basili, Briand \& Melo, 1996).The existing researches indicate a high level of OSS adoption (Bonaccorsi \& Rossie, 2003), (Dedrick \& West, 2003), (Gaffney \& Durek, 1989), (Hecker, 1999)], (Koltun \& Hudson, 1991), (Lawton, 2002), (Lewis, 1999), (Lussier, 2004), (Ruffin \& Ebert, 2004), Wang \& Wang 2001) both in commercial outlets and government organizations. Our exploratory study shows that for organizations to succeed and get a good share of the market, they have to provide products and services faster, cheaper, 
and better. One way of achieving this, is component reuse especially OSS component reuse. Many OSS adoption literatures shows that, in some aspects, reusing OSS as function components has more advantages than COTS reuse, such as low or none acquisition fee, peer review, customer involvement, life cycle, customizability, quality assurance, legal check, and so on.

In addition, there is a lot of OSS development and management tools available for software development projects to adopt. The most obvious places where OSS has an advantage in terms of costs are in the software acquisition costs, maintenance costs, and upgrade costs. OSS is almost always freely available, and usually has no license fees or annual maintenance fees (there are some exceptions, although they are not mandatory fees - they are generally for support) and upgrades are also generally free. However, the free acquisition costs of some OSS packages are by far outweighed by other kinds of costs (consultant time, staff training cost, administration cost, etc.), so software that is free is not necessarily less expensive in TCO terms than the software that you have to pay for. Therefore, how the degree of OSS adoption effects software development cost need be investigated.

Based on the claims of high-level OSS adoption, the success stories from literature review, and the results obtained from our initial study on the subject, we propose the following hypotheses:

$\mathrm{H} 1$ (a): There is a positive relationship between the degree of OSS adoption and software development cost efficiency.

$\mathrm{H} 1$ (b): There is a positive relationship between the degree of OSS adoption and software development productivity. 
H1 (c): There is a positive relationship between the degree of OSS adoption and software product quality.

\subsection{Maturity level of OSS adoption (H2 model)}

Component reuse is a powerful tool that can help significantly if employed correctly (Ajila, 2006), (Basili, \& Melo, 1996). The challenge however is how can we reuse OSS correctly? One way of measuring this is to look at the maturity level of OSS adoption processes. The maturity models support an assessment of how systematic OSS adoption is implemented. From literature reviews and interviews, incentives such as quality, cost, and time are often cited as motivations to adopt OSS (Lerner \& Tirole, 2002), (Lussier, 2004). For example, some mission critical projects reuse OSS heavily in order to improve quality (Norris, 2004). For this study, we have adapted the reuse maturity model developed by Koltun and Hudson (Koltun \& Hudson, 1991). This model defines phases of reuse maturity that is assumed to improve along an ordinal scale from 1 (initial/chaotic) to 5 (ingrained). It also defines dimensions of reuse maturity such as motivation/culture and planning for reuse (cf. appendix section 3). There are ten reuse dimensions and for each dimension an organization progresses from the initial/chaotic reuse to ingrained reuse. For example, ingrained reuse contains automated support tools and accurate measurements to track progress in reuse. An organization will normally use this model to place itself in terms of reuse improvement (Frakes \& Terry, 1996), (Koltun \& Hudson, 1991). Using the Koltun and Hudson (Frakes \& Terry, 1996), (Koltun \& Hudson, 1991) reuse maturity model provides three hypotheses relevant to OSS reuse maturity level: 


\begin{tabular}{|c|c|c|c|c|c|}
\hline & \multicolumn{5}{|c|}{ OSS adoption motivation levels } \\
\hline & Initial/Chaotic & Monitored & Coordinated & Planned & Ingrained \\
\hline $\begin{array}{l}\text { Motivation/Culture } \\
\text { of OSS adoption }\end{array}$ & Discouraged & Encouraged & $\begin{array}{l}\text { Re-enforced } \\
\text { rewarded }\end{array}$ & Indoctrinated & $\begin{array}{l}\text { Is the way do } \\
\text { business }\end{array}$ \\
\hline $\begin{array}{l}\text { Planning for OSS } \\
\text { adoption }\end{array}$ & None & $\begin{array}{l}\text { Grassroots } \\
\text { Activity }\end{array}$ & $\begin{array}{l}\text { Targets of } \\
\text { Opportunity }\end{array}$ & $\begin{array}{l}\text { Business } \\
\text { imperative }\end{array}$ & $\begin{array}{l}\text { Part of Strategic } \\
\text { Plan }\end{array}$ \\
\hline $\begin{array}{l}\text { Breadth of OSS } \\
\text { adoption }\end{array}$ & Individual & Work Group & Department & Division & Enterprise Wide \\
\hline $\begin{array}{lr}\text { Responsible } & \text { for } \\
\text { Making } & \text { OSS } \\
\text { adoption Happen }\end{array}$ & $\begin{array}{l}\text { Individual } \\
\text { Initiative }\end{array}$ & $\begin{array}{l}\text { Shared } \\
\text { Initiative }\end{array}$ & $\begin{array}{l}\text { Dedicated } \\
\text { Individual }\end{array}$ & $\begin{array}{l}\text { Dedicated } \\
\text { Group }\end{array}$ & $\begin{array}{l}\text { Corporate Group } \\
\text { with Division } \\
\text { Liaisons }\end{array}$ \\
\hline $\begin{array}{l}\text { Process by Which } \\
\text { OSS adoption is } \\
\text { Leveraged }\end{array}$ & $\begin{array}{l}\text { OSS adoption } \\
\text { Process } \\
\text { Chaotic, } \\
\text { Unclear how } \\
\text { OSS adoption } \\
\text { Comes in. }\end{array}$ & $\begin{array}{l}\text { OSS adoption } \\
\text { Questions } \\
\text { Raised at } \\
\text { Design } \\
\text { Reviews } \\
\text { (After the } \\
\text { fact) }\end{array}$ & $\begin{array}{l}\text { Design } \\
\text { emphasis } \\
\text { placed on OSS } \\
\text { Adoption }\end{array}$ & $\begin{array}{l}\text { Focus on } \\
\text { developing } \\
\text { families of } \\
\text { projects }\end{array}$ & $\begin{array}{l}\text { All software } \\
\text { projects are } \\
\text { generic for future } \\
\text { OSS Adoption }\end{array}$ \\
\hline $\begin{array}{l}\text { Metrics } \\
\text { Adoption }\end{array}$ & $\begin{array}{l}\text { No Metrics on } \\
\text { Adoption } \\
\text { Level, pay-off, } \\
\text { or costs }\end{array}$ & $\begin{array}{l}\text { Number of } \\
\text { Lines of code } \\
\text { used in cost } \\
\text { models }\end{array}$ & $\begin{array}{l}\text { Manual } \\
\text { tracking of } \\
\text { adoption } \\
\text { occurrences of } \\
\text { catalog parts }\end{array}$ & $\begin{array}{l}\text { Analyses } \\
\text { done to } \\
\text { identify } \\
\text { expected } \\
\text { payoffs from } \\
\text { developing } \\
\text { reusable parts }\end{array}$ & $\begin{array}{l}\text { All System } \\
\text { Utilities, } \\
\text { software tools } \\
\text { and accounting } \\
\text { mechanisms } \\
\text { instrumented to } \\
\text { track adoption }\end{array}$ \\
\hline
\end{tabular}

(Source: Frakes and Terry, 1999)

H2 (a): OSS adoption maturity level is positively related to software development cost efficiency.

$\mathrm{H} 2$ (b): OSS adoption maturity level is positively related to software development productivity.

$\mathrm{H} 2$ (c): OSS adoption maturity level is positively related to software product quality. 


\subsection{Skill and experience of OSS adoption (H3 model)}

A number of researchers have explored the reasons why systematic adoption succeeds or fails (Basili, Briand \& Melo, 1996), (Crnkovic \& Larsson, 2002), (Frakes \& Terry, 1996), (Gaffney \& Durek, 1989). The factors identified include adequate tool support, level of management support, organizational adoption, and software evaluation experience, metrics, incentives, and development standards. To date, there is no research on what role skill and experience play in OSS adoption. Judging from our exploratory interview and literature review on systematic adoption, we posit the following hypotheses:

$\mathrm{H} 3$ (a): OSS adoption Skill and experience level is positively related to software development cost efficiency.

$\mathrm{H} 3$ (b): OSS adoption skill and experience level is positively related to software development productivity.

H3 (c): OSS adoption Skill and experience level is positively related to software product quality.

\subsection{Selection criteria of OSS (H4 model)}

From our initial exploratory study and literature review, we found that OSS adoption raises a number of issues (Ajila, 2006), (Basili, \& Melo, 1996), (Bonaccorsi \& Rossie, 2003), (Dedrick \& West, 2003), (Gaffney \& Durek, 1989), (Madanmohan \& De, 2004), (Wang, 2001), (Witten, Landwehr \& Caloyannides, 2001), (Wu \& Lin, 2001). Notables are requirement negotiation and components selection. The most critical is the selection criteria. Project and quality managers suggest that 'quantified selection 
criteria and acceptable thresholds are very important in reuse process.' The software developers we interviewed first identified OSS components for reuse based on if they satisfied functional requirements and later considered the issue of usability and cost. However, there is no agreement on what method is best for selecting OSS components for reuse. In general, there are three approaches - (i) selection based on functional requirements - these are functionality, efficiency, speed, of execution, organization standards, and preference; (ii) selection based on technical requirement - this includes availability of technical support, future upgrade, customization, and reliability; and (iii) selection based on management requirements - these are budgetary issues, development team experience, license, and maintainability (Basili, \& Melo, 1996), (Dedrick \& West, 2003), (Madanmohan \& De, 2004), (Wang, 2001). Due to the importance of selection criteria in reuse process, we propose the following three research hypotheses for OSS adoption selection:

H4 (a): OSS adoption selection criteria are positively related to software development cost efficiency.

H4 (b): OSS adoption selection criteria are positively related to software development productivity.

H4 (c): OSS adoption selection criteria are positively related to software product quality.

\subsection{OSS adoption in small and large sized organizations (H5 model)}

Software process plays an important role in the coordination of software development teams (Ajila \& Bailetti, 2006), (Royce, 1998). Software Process Improvement (Royce, 1998) is a conscious effort to change an organization's software processes so 
that they meet the organization's business objectives and help it to achieve its business goals more efficiently. More over Software Process Improvement (SPI) can be expressed as a qualitative measurement by which a software company can measure its level of success. Due to this, one can argue that the size of a software company should reflect its financial success or a successful reputation (Lerner \& Tirole, 2002). For a smaller company to obtain the success of a large sized company, it would be reasonable to propose that a smaller company should strive towards implementing the same SPI and knowledge reuse strategies as a large sized company (Lawler III, 1997). This however may not be the case, as there is no substantial evidence that supports the claim that small software organizations should implement the same SPI and adoption strategies as larger software organizations to be successful. Previous studies in TQM implementation show that the experiences of small firms differ to that of large firms and that human resource plays a large role in the differences (Ahire \& Golhar, 1996), (Richardson, 2001). It is also important to note that small firms are not just 'scaleddown' versions of large firms (Richardson, 2001). In addition, software development is driven by the knowledge of those developing it and because of an ever changing technology market this knowledge must be maintained and always increasing. Also process emphasizes control while practice without process can sometimes lead to chaos. Accordingly, there is a problem of balancing between formal (process) and informal (without process) and between small and large software development teams. It is necessary then to examine if the size of a software firm with OSS adoption has impacts on software development economics. So, we posit:

H5: There is difference between small and large sized organizations when adopting OSS. 


\section{RESEARCH METHOD}

\subsection{Unit of analysis}

The unit of analysis for this research is the software development project which adopts OSS.

\subsection{Research method}

This research proceeded through all the three steps in the descriptive stage of Chrtiensen's "Theory Building Processes" (Figure 2). In the first step, which is observation, this research followed two parallel but complimentary dimensions. In the first place, we carried out an extensive literature review within the fields of open source software development, open source contributions, open source adoption, software component reuse, organizational issues, quality management, software project management, security, and OSS licensing issues. In addition to the literature review, we undertook an exploratory field study through interview with project managers, quality managers, and senior developers in six software development organizations that adopt OSS in their software development project (figure 3). The goal was to find out whether they are interested in the research question and what kind of outcomes they were looking for vis-à-vis software development economics and OSS adoption.

In the second step, which is classification, we categorized, constructed and abstracted these theories and studies, which are related to OSS adoption and software development project management in order to understand what OSS adoption variables are likely to affect software development economics. 
In the third step, which is association, we formulated the research model, hypotheses, and initial survey questionnaire, which associate the variables and the outcomes.

Then we returned to the literature review and preliminary interview review to see if the questionnaire is applicable.

Lastly, after we collected enough data by survey questionnaires, we used the correlation and regression analysis techniques for data analysis to make probabilistic statements, formed the basis of empirical analysis reported and find some anomalies. We then returned to step one again to see if we could find some clues to link to the anomalies, which could be used for future researches.

Figure 2: Process of building theory

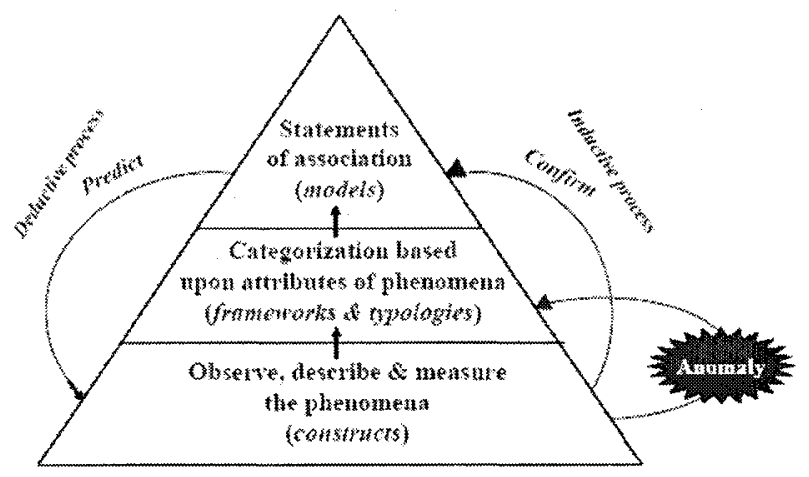

(Source: Carlile \& Christensen, 2005)

\subsection{Preliminary Interview}

Our initial survey was done through a process of interviewing project managers, quality managers, and senior developers from six software organizations (Figure 3). 
This was carried out between September and December, 2004. The interview selection was done through a convenience and judgment sampling. Convenience and judgment sampling is used in exploratory research where the researcher is interested in getting an initial inexpensive approximation of the truth. The objective in the interview is to understand how OSS adoption is done, what criteria are used in the selection process, and what level of skill and experience is required when selecting OSS components for adoption. We also seek to understand the motivation behind the decision to adopt OSS in the development of software. Our choice of project managers, quality managers, and senior developers are based on the fact that they are involved in the development of software from conception to deployment. In most cases, they are also involved in the maintenance and after delivery service of the software. We began each interview by introducing our motivations and we avoided introducing any hypothesis so that the interviewee would not be biased. We then analyzed each interview transcript and ask for corrections from the interviewee. All together we interviewed 18 people (six in each category - project manager, quality manager, and senior developer). The result of our interview and literature review provided insight into the following questions:

- Why did you adopt Open Source software?

- At what level of the development cycle did you decide the type of OSS components to adopt?

- How did you locate and select OSS components for adoption?

- At what level of the organization management level was the decision taken to adopt OSS? 
- What are the gains in terms of productivity, time to market, money, and quality?

- How did you resolve licensing issues when adopting OSS?

- How do you measure your project outcomes, such as product quality, software development productivity and cost efficiency.

Each interview session lasted between 40 to 60 minutes and we offered to give the interviewees the result of our investigations. Nine of the interviews were conducted face to face, six by telephone and three through e-mail.

\subsection{Population and sample}

The Software intensive IT companies from Canada and the U.S. which have at least 20 software developers were targeted population for this study. Figure 3 shows the population and sampling methods used in this research. This population includes organizations with different sizes, either developing software or combined software and hardware products for a variety of markets and for in-house use. The period of study is between September, 2004 and March, 2006.

Figure 3: Population and sampling method

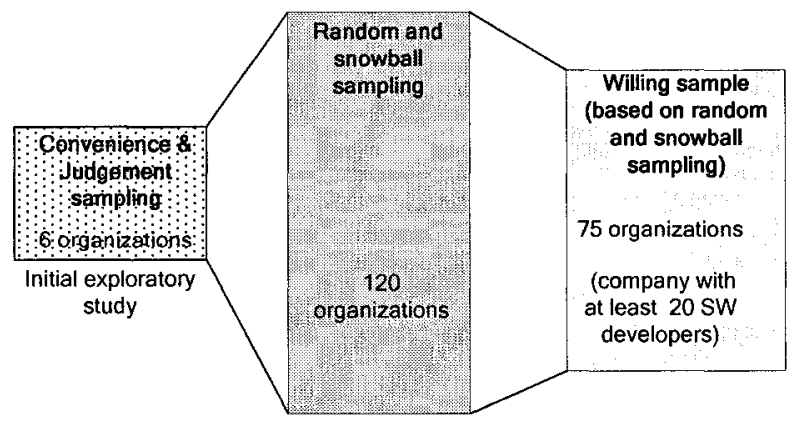

The recruitment was carried out in two ways: i) through a random selection of IT companies of the Ottawa Centre for Research and Innovation (OCRI) corporate 
members profile and Canada IT directories and. ii) By contacting directly potential respondents through snowball methodology.

The starting points are the people who are involved in the relevant projects. Each of them was asked to refer other key person they know in other companies, who has done the same kind of project. The initial groups of the snowball resemble as closely as possible a random or stratified random sample. For instance, the information on OSS community web was used to get information which company used their SW, and which companies are their sponsors. Then, all of these companies serve as an initial group were contacted to fill the questionnaire and then asked to refer other people. The software companies in member directory of Ottawa Centre for Research and Innovation (OCRI) partnership organizations were also used as part of the initial groups.

In April 2005, a random sample of 120 software intensive organizations from Canada and the U.S. were contacted through e-mail and requested their participation in the study prior to sending the survey questionnaires (figure 3). We included our goals based on our initial exploratory investigations in the e-mails and requested either the project manager, the quality manager, or one senior developer to complete the questionnaire. A total of 85 organizations agreed to participate in the study, but only 75 qualified in terms of the number of software developers (20 or more) and involvement in large scale OSS adoption. Out of these 75 organizations, 60 completed and returned the questionnaire successfully (figure 3). The respondents companies represent different sectors of the IT industries. To a large extent, these organizations have developed software for external customers (60\% of the sample) and internal use 
for their hardware/communication products (40\% of the sample). Furthermore, the sample shows a mix of small to large organizations with $30 \%$ having 20-39 software developers and 50\% having 40-59 software developers, and $20 \%$ having 60 or more software developers. In total, $36(48 \%)$ of the sample are large sized organizations with 1000 or more employees while $39(52 \%)$ are small/medium sized organizations. The 60 returned and usable questionnaires are evenly divided between large and small/medium sized organizations. In addition close to $60 \%$ of the sampled companies have offices in Europe, Asia, and the Middle East. About $20 \%$ have subsidiaries in Africa.

\subsection{Questionnaire}

Project managers, team leaders, senior software engineers/developers who are involved in the project and have in-depth knowledge of the development process are targeted as respondents to answer the questionnaire. These managers and developers are involved in the development of software as well as in the software maintenance.

The questionnaire was reviewed and received ethics clearance through the Carleton University Research Ethics Committee.

The questionnaires were sent to potential respondents by e-mail. Completed questionnaires were also received via e-mail, and then e-mail or phone call were used to make sure that they complete correctly.

\subsection{Variables}


Combining the result of our exploratory interviews and literature review we identified four independent variables, two dependent variables, and one control variable. Figure 4 shows the research model and the associated hypotheses.

\subsubsection{Independent variables}

The following four variables were identified and used:

\section{Degree of OSS adoption}

- OSS adoption level in product architecture, platforms, core functional development, design pattern, tools, testing, and document.

We use 7-point Likert scale to rate at the level of OSS adoption. "1" and "2" means not sure and not at all. "7" means with OSS very high adoption.

\section{OSS adoption maturity level}

- OSS adoption maturity level based on Koltun and Hudson maturity model (Koltun \& Hudson, 1991).

We apply Koltun and Hudson maturity assessment model to make ordinal scale from 1 (Initial/Chaotic) to 5 (Ingrained).

\section{OSS adoption skill and experience}


- The extent to which developers' skill and experience in OSS adoption impacts development cost, productivity and product quality.

We use 7-point Likert scale to rate at the level of experiences and skills about OSS adoption. "1" means no experience and/or skill. "7" means highly experienced and/or skilled.

\section{OSS adoption selection criteria}

-The extent to which functional, technical, and management requirements influence OSS components adoption.

We use 7-point Likert scale to rate the importance in 4 main software development activities. These are idea generation and screening, requirements definition and design specification, technical development, trials and testing. The scales "1" and "2" means not sure or not important, "7" means with very important.

To measure the extent to which these four independent variables are performed, we used seven-point and five-point specialized Likert scales and other scales (see appendix). Item ratings were summarized to form an average (overall) rating scale for each independent variable.

\subsubsection{Dependent variables}

According to Pressman, metrics for measuring software development performance fall into three categories: process metrics, project metrics, and product metrics (Pressman, 
1997). In particular, software development productivity, cost efficiency and product quality are used as the major metric to measure software development economics. Therefore, we identified the three dependent variables: software development productivity, cost efficiency and product quality. Each manager was asked to rate, on a 5-point bipolar Likert scales, how success meets goals vis-à-vis development cost efficiency, productivity and product quality. The scale ranges from (1) cannot rate to (5) exceeded all expectations. The ratings for each variable were averaged to form a single measure of overall for cost efficiency, productivity and quality.

In addition, for the considerations of validity, we also use some real metrics to confirm if there are some biases or misunderstandings for the answers.

In the literature review of software engineering, we found two metrics are most often used to measure software product size: Line of Code (LOC) and Function Points (FP) (Kan, 2003). LOC is simple and easy to collect, but difference among programming languages will have huge variations in the counting of LOC. Function Point is the total number of functions provided in a given software product, in which case, function can be considered as a collection of executable statements of software that performs a certain task, together with declarations of the formal parameters and local variables manipulated by those statements (Conte and Shen, 1986). In this research, FP is used as the metric to measure software project size, as it is independent of programming languages. It can provide more accurate results since it uses readily countable characteristics of software project that makes it easier to accommodate reuse and object-oriented approaches. 
Participants in this research can indicate the size of their projects by either LOC or FP. In the data analysis, LOC will be converted to FP based on QSM Function Point Programming Languages Table (Pressman, 1997). As is widely used in software engineering literature, Person Month (Number of person involved in project multiply development time) will be used to measure software development efforts.

We use development efforts divide software project size to verify Software development productivity:

Productivity $=$ Software project size $/$ Development Efforts $=$ KSLOC $/$ Hours

(KSLOC) is Manhours per 1,000 software lines of code

And we use of Fault Density (Faults/KSLOC) plus Error Density (Errors/KSLOC) to verify product quality (Frakes and Terry, 1996):

Quality = Fault Density (Faults/KSLOC) +Error Density (Errors/KSLOC)

\subsubsection{Control variable}

Company size was measured using three parameters: number of software developers working for the organization, the overall size of the organization, and annual revenue. The companies with annual revenue under 10 million dollars and total number of employees under 100 were counted as small company. 
Figure 4: Research model

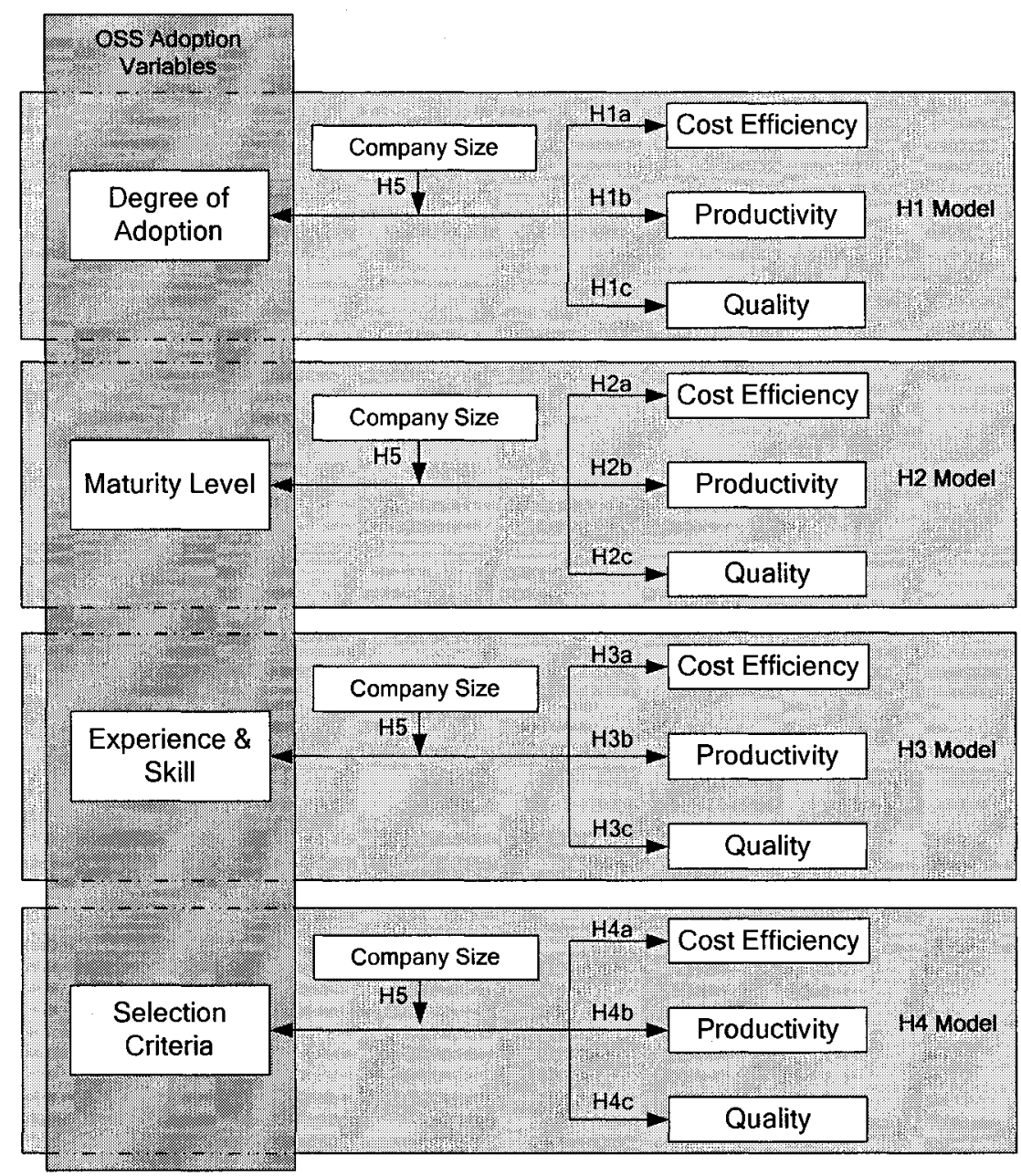

\subsection{Likert Scale and Scoring}

In this research work, we used Likert scale to design the questionnaire as well as scoring and analysis of the response. A Likert scale is a form of psychometric response scale used in questionnaires and is the most widely used scale in survey research. The scale was developed by Rensis Likert (a sociologist) in 1932 for the purposes of measuring psychological attitudes in a scientific way. Likert scaling is a bipolar scaling method used for measuring either positive or negative response to a 
statement. Traditionally, a five-point scale is used: strongly disagree, disagree, neutral, agree, and strongly agree.

Responses to a single Likert statement are treated as ordinal data and analyzed using non parametric tests. Responses to several Likert items are summed and they are treated as interval data measuring a latent variable. If the responses are normally distributed, parametric tests can be applied. In this work, we summed the responses and treated them as intervals. In addition, we used parametric statistics such as Pearson product-moment correlation coefficient and t-tests because examination of the skewness and kurtosis indicates that the sample data for all the variables are normally distributed (cf. table 7 in chapter 5). We tested the validity of our approach by using non-parametric Mann-Whitney test and Wilcoxon $U$ test to analysis the effects of company size on OSS adoption. The results of this test give the same conclusion as we have in table 7 using parametric t-test. 


\section{RESULTS, ANALYSIS, AND DISCUSSION}

The main concern of the analysis is to determine the effects of OSS adoption on software development cost efficiency, productivity, and product quality. In other words, we want to know the impacts of OSS adoption on software development economics. Thus, we defined relationships between the different variables and between small to medium and large sized organizations (see figure 4). Figure 4 is divided into four models $(\mathrm{H} 1, \mathrm{H} 2, \mathrm{H} 3$, and $\mathrm{H} 4)$ based on the hypotheses tests set (cf. tables $8,10,12$ and 13). We started the analysis by testing for normality (table 7). Examination of the skewness and kurtosis indicates that the sample data for all the variables are normally distributed. Table 7 also presents the Pearson product-moment correlation coefficient for all the study variables and average extracted variance for each construct. The analysis in table 7 represents the average (overall) for each of the independent variable. We also used parametric statistics such as Pearson productmoment correlation coefficient to analyze the models (cf. tables 8, 10,12 and 13) and the t-test (cf. table 15) to analyze the difference of means between small and large sized organizations. Then we used one multiple regression per outcome measure (see table 9,11 and 14) to examine multi-colinearity, by computing all pair-wise correlations to see which predictors are correlated. The result of the tests showed that all variables were within the acceptable range for the normal distribution assumption, and that linearity and independence of the error terms were supported. In addition, we did not identify any influential observations that indicate a violation of the basic assumptions underlying the chosen data analysis techniques. 
5.1 H1 Model: Hypotheses H1 (a, b \& c)

To examine whether there is a positive relationship between the degree of OSS adoption and software development economics (cost, productivity, and quality), we carried out Pearson correlation test (see table 8) on the level of OSS usage in the development activities vis-à-vis development cost efficiency, productivity and product quality. Overall average analysis in table 7 strongly supports hypothesis H1(c) with a statistically significant strong correlation $(r=0.573, p<0.01)$ between the degree of OSS adoption and product quality. Hypotheses H1 (a \& b) are not supported by the analysis in table 7 but, we cannot yet reject the two hypotheses until we look at the $\mathrm{H} 1$ model analysis in table 8 . Table 8 supports the analysis in table 7 with respect to strong correlation between degree of OSS adoption and software quality. In terms of software testing, platform, and documentation, table 8 shows significant statistical positive relationship between the degree of OSS adoption and cost of software development. Similarly, software productivity is positively impacted through two attributes - core functionality and platform. Somehow, core functionality attribute is not statistically significant with respect to software quality and design pattern is negatively correlated with cost efficiency.

\begin{tabular}{|c|c|c|c|c|c|c|c|c|c|c|c|}
\hline Mean & S.D. & & $(N=60)$ & 1 & 2 & 3 & 4 & 5 & 6 & 7 & 8 \\
\hline 3.6902 & 1.1654 & 1 & Degree of adoption & 1 & & & & & & & \\
\hline 2.8200 & .9920 & 2 & Maturity level & $.737^{* * *}$ & 1 & & & & & & \\
\hline 2.7083 & .87596 & 3 & Experience \& skill & $.595 * *$ & $.633^{* *}$ & 1 & & & & & \\
\hline 2.8000 & .84973 & 4 & Selection criteria & $.845 * *$ & $.646^{* *}$ & $.490 * *$ & 1 & & & & \\
\hline 2.5700 & .9630 & 5 & Cost efficiency & .241 & .128 & .169 & $43 I^{*}$ & 1 & & & \\
\hline 2.8000 & .7080 & 6 & Productivity & .193 & $349^{* *}$ & .068 & .115 & .119 & 1 & & \\
\hline 2.7700 & .8900 & 7 & Quality & $573^{* *}$ & $431 \%$ & $292 *$ & $565 \%$ & $.473^{* *}$ & .140 & 1 & \\
\hline \multirow{6}{*}{1.5000} & .5040 & 8 & Company size & .004 & -.243 & -.086 & -.119 & -.105 & $-.475^{* *}$ & -.113 & 1 \\
\hline & & & Variance extracted & 1.358 & .983 & .767 & .722 & .928 & .502 & .792 & .254 \\
\hline & & & Skewness statistics & .608 & .318 & .124 & 728 & -.666 & -.876 & -.411 & .000 \\
\hline & & & Skewness std. error & .309 & .309 & .309 & .309 & .309 & .309 & .309 & .309 \\
\hline & & & Kurtosis statistics & -.502 & -.411 & -.758 & -.634 & -.731 & 1.209 & -.433 & -2.070 \\
\hline & & & Kurtosis std. error & .608 & .608 & .608 & .608 & .608 & .608 & .608 & .608 \\
\hline
\end{tabular}


The results (tables 7 and 8 ) show that the degree of OSS adoption is moderately high (mean $=3.6902, \mathrm{SD}=1.1654)$ compared to other independent variables.

Specifically, the strongest positive effect is on software quality followed by development productivity, and some level of supports for development costs. This result is consistent with our initial exploratory study through interview with project and quality managers, and senior developers. There was a consensus among software developers that OSS components are of highest quality and adopting them contributes significantly to the end product quality. Also, there was agreement that OSS adoption somewhat significantly to productivity in terms of reduce time to market. However, there are no significant positive impacts of OSS adoption on software development cost efficiency. This result also confirms the case studies, the experience reports, some other success stories in the literature (Bonaccorsi \& Rossie, 2003), (Dedrick \& West, 2003), (Hecker, 1999), (Madanmohan \& De, 2004), (Norris, 2004), (Raymond, 1999), (Stone, 2002). Furthermore, attributes such as platform and documentation have positive impacts on software development economics vis-à-vis degree of OSS adoption. This outcome is supported by studies on the effects of OSS such as Linux and Apache web server on critical software development in a commercial setting (Dedrick \& West, 2003), (Fitzgerald \& Kenny, 2004), (Hecker, 1999), (Kshetri, 2004), (Leavitt, 2001), (Lerner \& Tirole, 2002), (Lussier, 2004), (Norris, 2004), (West, 2003). There is no denying the fact that some people believe that the short run gain in cost through OSS adoption is a long run spending on maintenance, security, and licensing (Gacek \& Arief, 2004), (Glass, 1999), (Lawton, 2002), (Lewis, 1999), (Witten, Landwehr \& Caloyannides, 2001). Although our work did not study maintenance, security, and licensing specifically but our result so far indicates a strong positive 
impacts on software product quality which, indirectly reduces the cost of maintenance and security. It could also be argued that the issue of licensing is not limited to OSS alone but a global problem in software development.

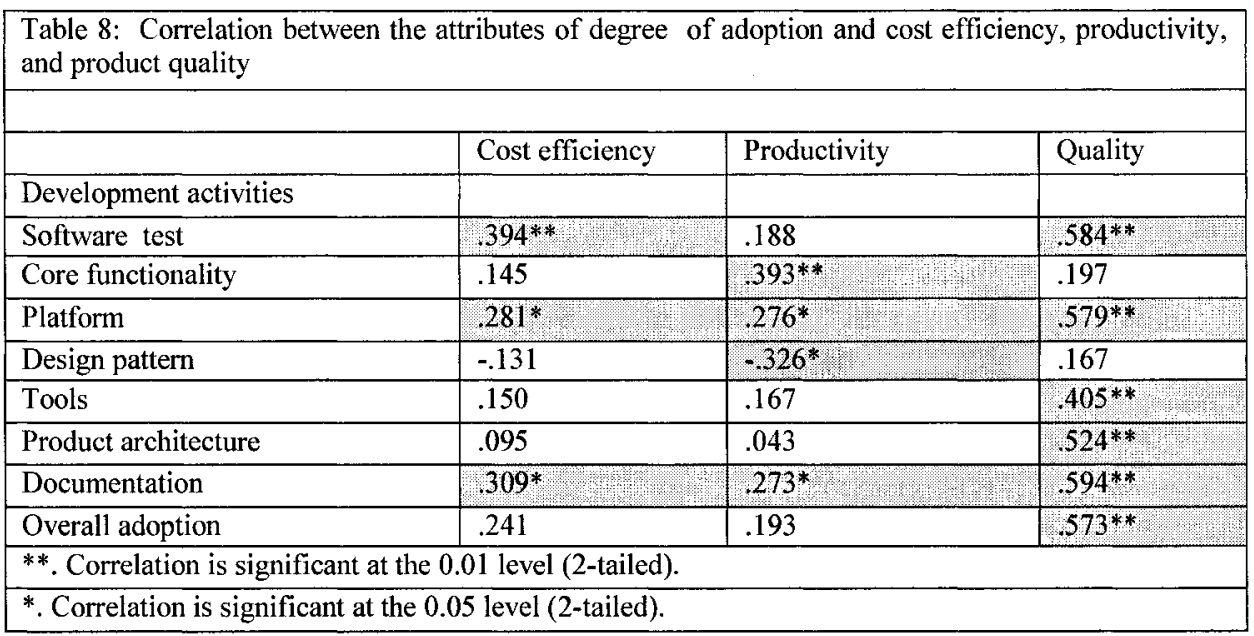

H1c can be further tested by the linear regression, which builds a linear model to describe the relationship between degree of OSS and software development (SWD) end product quality. The linear regression specification of $\mathrm{H} 1 \mathrm{c}$ is that:

SWD end product quality $=\alpha+\beta$ (degree)

\begin{tabular}{|l|l|l|l|l|}
\hline Table 9: Results of linear regression analysis for $\mathrm{H} 2 \mathrm{c}$ \\
\hline Adoption level & $\mathrm{R} 2$ (adjusted) & $\mathrm{F}$ & Estimate of $\alpha$ & Estimate of $\beta$ \\
\hline Product quality & .329 & 13.714 & $1.151^{* * *}$ & $.438 * * *$ \\
\hline${ }^{*} \mathrm{p}<0.1,{ }^{* *} \mathrm{p}<0.05,{ }^{* *} \mathrm{p}<0.01$
\end{tabular}

Table 9 presents the results of the linear regression analysis of Hlc. In such result, the estimate of $\alpha$ and $\beta$ are significant and they have the hypothesized sign, which suggest that there is linear relationship between SWD end product quality and degree of OSS adoption. The best-fit linear equation for the regression - SWD end product quality against the degree of OSS adoption is: 
SWD end product quality $=1.151+.438($ degree $)$

Based on the data, software development end product quality will be higher when the degree of OSS adoption is high. The positive slope of the relationship between the degree of OSS adoption and software development end product quality supports H1c.

\subsection{H2 Model: Hypotheses H2 (a, b \& c)}

To examine the effects of adoption maturity level on development economics, we correlate the motivation level of six dimensions of maturity level developed by Koltun and Hudson (Koltun \& Hudson,1991) on development productivity, product quality and cost efficiency (see table 10). In the overall analysis and result (cf. table 7), there were strong statistical correlations $(r=0.349, p<0.01$ and $r=0.431, p<0.01)$ between OSS adoption maturity and two dependent variables - productivity and quality. These results support hypotheses $\mathrm{H} 2$ (b) and H2(c). At this overall average level H2 (a) is not supported. The result of $\mathrm{H} 2$ model analysis in table 10 confirms the result in table 7 . What is important here is that the developers are highly motivated to adopt OSS judging from the results in table 10. For example, looking at the development productivity; maturity dimensions such as adoption culture, adoption plan, and adoption breadth show strong statistical significances. Similarly, the correlations are equally stronger on product quality when it comes to adoption culture, adoption breadth, and responsibility for adoption. Interestingly, there is no strong statistical correlation between adoption plan and product quality. Overall, the OSS adoption maturity level is high and its impact on productivity and quality is equally very strong. This result is consistent with the observation made by Frakes and Terry 
(Frakes \& Terry, 1996) that "Once an organization achieves ingrained reuse, reuse becomes part of the business routine and will no longer be recognized as distinct discipline." This is also consistent with our initial findings from the exploratory study that "OSS adoption is serious and that top management is directly involved in the adoption process by encouraging their line managers to adopt open source components."

\begin{tabular}{|c|c|c|c|}
\hline & $\begin{array}{l}\text { Cost } \\
\text { efficiency }\end{array}$ & Productivity & Quality \\
\hline \multicolumn{4}{|l|}{ Maturity dimensions } \\
\hline Culture & .219 & $350^{* *}$ & $361 * *$ \\
\hline Adoption plan & .059 & $321 * ? \div$ & .192 \\
\hline Adoption breadth & .191 & $369 * *$ & $550^{* *}$ \\
\hline Make it happen & .136 & .202 & $.416^{* *}$ \\
\hline Adoption leverage & .027 & .216 & $257^{*}$ \\
\hline Control metrics & -.051 & .154 & .172 \\
\hline Overall maturity level & .128 & $349 * *$ & $43.1 * *$ \\
\hline
\end{tabular}

$\mathrm{H} 2 \mathrm{~b}$ and $\mathrm{H} 2 \mathrm{c}$ can be further tested by the linear regression, which builds a linear model to describe the relationship between degree of OSS and software development end product quality and productivity.

The linear regression specification of $\mathrm{H} 2 \mathrm{~b}$ is that:

$$
\text { SWD Productivity }=\alpha+\beta \text { (motivation level) }
$$

The linear regression specification of $\mathrm{H} 2 \mathrm{c}$ is that:

$$
\text { SWD end product quality }=\alpha+\beta \text { (motivation level) }
$$

\begin{tabular}{|l|l|l|l|l|}
\hline \multicolumn{6}{|l|}{ Table 11: Results of linear regression analysis for $\mathrm{H} 2 \mathrm{~b}$ and $\mathrm{H} 2 \mathrm{c}$} \\
\hline Motivation level & $\mathrm{R} 2$ (adjusted) & $\mathrm{F}$ & Estimate of $\alpha$ & Estimate of $\beta$ \\
\hline SWD productivity & .122 & 3.886 & $2.098^{*}$ & $249^{*}$ \\
\hline Product quality & .185 & 6.373 & $1.678^{* * *}$ & $.387^{* * *}$ \\
\hline
\end{tabular}


Table 11 presents the results of the linear regression analysis of $\mathrm{H} 2 \mathrm{~b}$ and $\mathrm{H} 2 \mathrm{c} \mathrm{c}$. In such result, the estimate of $\alpha$ and $\beta$ are significant and they have the hypothesized sign, which suggest that there is linear relationship between SWD end product quality and OSS adoption motivation level and there is also linear relationship between SWD productivity and OSS adoption motivation level.

The best-fit linear equation for the regression - SWD end product quality against the OSS adoption motivation level is:

$$
\text { SWD end product quality }=1.678+.387 \text { (level) }
$$

The best-fit linear equation for the regression - SWD productivity against the OSS adoption motivation level is:

$$
\text { SWD productivity }=2.098+.249(\text { level })
$$

Based on the data, the positive slope of the relationship between the OSS adoption motivation level and software development end product quality and between the OSS adoption motivation level and software development productivity supports $\mathrm{H} 2 \mathrm{~b}$ and $\mathrm{H} 2 \mathrm{c}$.

5.3 H3 Model: Hypotheses H3 (a, b \& c)

Hypothesis H3(c) is supported by the result in tables 7 and 12. However, H3 (a) and H3(b) are not supported by the result in table 7 while table 12 shows that there is some level of statistical correlations $(\mathrm{p}<0.05$ and $\mathrm{p}<0.01)$ in technical development, and in trials and testing vis-à-vis software development cost. With the exception of 
technical development and testing, our findings did not show strong statistical significance between developers' experience on OSS adoption and software development economics. This is contrary to our initial survey result that "skill and experience are very important in the adoption process." In addition, these findings did not appear to be in synch with literature review on adoption process (Ajila, 2006), (Basili, \& Melo, 1996), (Crnkovic \& Larsson, 2002), (Frakes \& Terry, 1996), (Gaffney \& Durek, 1989), (McArthur, 2002). We will like to assert that OSS adoption does not need a special skill and experience other than what is needed for software adoption in general. We came to this assertion due to the fact that those organizations adopting OSS do have experience in general software components reuse before switching to OSS adoption.

\begin{tabular}{|c|c|c|c|}
\hline & Cost efficiency & Productivity & Quality \\
\hline \multicolumn{4}{|l|}{ Development activities } \\
\hline Idea generating and screening & -.093 & .132 & .090 \\
\hline Requirements definition and design specification & .023 & .049 & .180 \\
\hline Technical development & $.301^{*}$ & .056 & $356 * *$ \\
\hline Trials and testing & $366 * * 2$ & -.029 & $342 * *$ \\
\hline Overall skill and experience level & .169 & .068 & $.292^{*}$ \\
\hline
\end{tabular}

\subsection{H1 Mode4: Hypotheses H4 (a, b \& c)}

Hypotheses H4 (a) and H4(c) are supported (cf. tables 7 and 13). Hypothesis H4 (b) is not supported and there is no significant statistical correlation coefficient in any of the selection criteria attributes vis-à-vis productivity (table 13). There is a very strong relationship between selection criteria and product quality in the sense that all the attributes of selection criteria show very high significant correlations $(p<0.01)$ with product quality. This shows that the bias exhibited in some quarters concerning the 
quality of OSS is unfounded (Glass, 1999), (Lawton, 2002), (West, 2003) as far as this study is concerned. This study also confirms the reasons why organizations adopt OSS (Bonaccorsi \& Rossie, 2003), (Dedrick \& West, 2003), (Kshetri, 2004), (Lussier, 2004), (Madanmohan \& De, 2004), (Scacchi, 2004). We can see from this result that the major motivation for adoption is essentially quality and closely in the second place is cost efficiency. This result also complements previously established results concerning the quality of OSS components (Hecker, 1999), (Kshetri, 2004), (Lerner \& Tirole, 2002), (Lussier, 2004), (Raymond, 1999), (Stone, 2002).

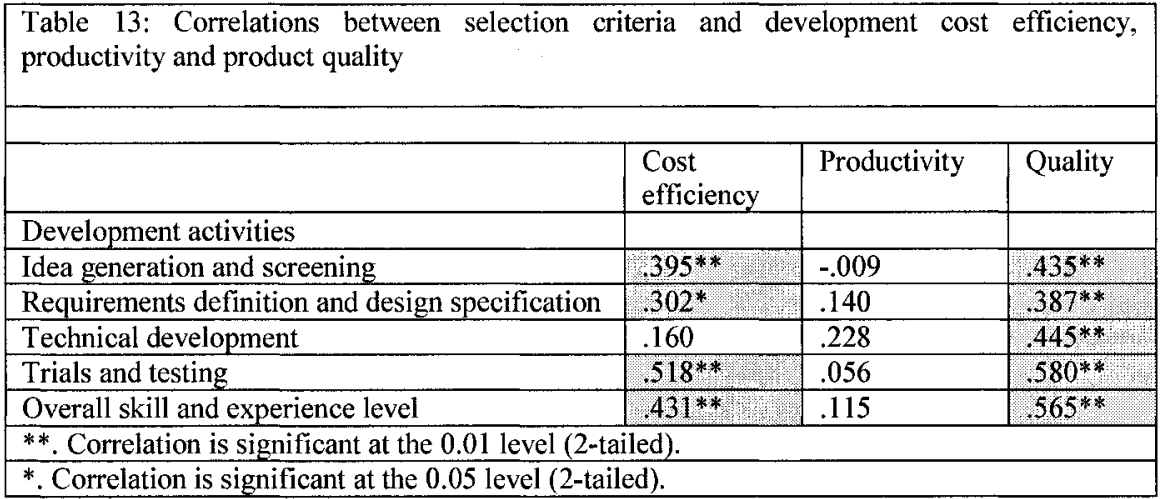

$\mathrm{H} 4 \mathrm{a}$ and $\mathrm{H} 4 \mathrm{c}$ can be further tested by the linear regression, which builds a linear model to describe the relationship between OSS selection criteria and software development cost efficiency and end product quality.

The linear regression specification of $\mathrm{H} 4 \mathrm{a}$ is that:

$$
\text { SWD Productivity }=\alpha+\beta \text { (development cost efficiency) }
$$

The linear regression specification of $\mathrm{H} 4 \mathrm{c}$ is that:

SWD end product quality $=\alpha+\beta$ (importance of selection criteria) 


\begin{tabular}{|l|l|l|l|l|}
\hline \multicolumn{5}{|l|}{ Table 14: Results of linear regression analysis for H4a and H4c } \\
\hline Motivation level & R2 (adjusted) & F & Estimate of $\alpha$ & Estimate of $\beta$ \\
\hline SWD cost efficiency & .186 & 6.379 & $1.200^{* * *}$ & $.488^{* * *}$ \\
\hline Product quality & .319 & 13.115 & $1.110^{* * *}$ & $.592^{* * *}$ \\
\hline
\end{tabular}

Table 14 presents the results of the linear regression analysis of $\mathrm{H} 4 \mathrm{a}$ and $\mathrm{H} 4 \mathrm{c}$. In such result, the estimate of $\alpha$ and $\beta$ are significant and they have the hypothesized sign, which suggest that there is linear relationship between SWD end product quality and the importance of OSS selection criteria and there is also linear relationship between SWD cost efficiency and the importance of OSS selection criteria.

The best-fit linear equation for the regression - SWD end product quality against the importance of OSS selection criteria is:

SWD end product quality $=1.11+.592($ importance of OSS selection criteria) The best-fit linear equation for the regression - SWD cost efficiency against the OSS adoption motivation level is:

SWD cost efficiency $=1.2+.488$ (importance of OSS selection criteria)

Based on the data, the positive slope of the relationship between the importance of OSS selection criteria and software development end product quality and between the importance of OSS selection criteria and software development cost efficiency supports $\mathrm{H} 4 \mathrm{a}$ and $\mathrm{H} 4 \mathrm{c}$.

\subsection{Hypotheses H5}


Finally, to examine whether a software organization's size affects the way OSS adoption is done, we compared small $(\mathrm{N}=30)$ and large $(\mathrm{N}=30)$ organizations. The effects of organization size were examined by testing for the difference of means between the small and large sized organizations using two-tailed t-tests. Results of these tests are summarized in table 15. The table provides mean score, standard deviation, and t-value for each group. As can be seen, both small and large sized organizations reported the same level of effects. Statistically significant difference is observed in maturity level and in software development productivity where small organizations reported higher level of effects $(t=1.905, p<0.05 ; t=4.106, p<0.01)$ than in large sized organizations.

\begin{tabular}{|c|c|c|c|c|c|}
\hline \multirow{2}{*}{$(\mathrm{N}=60)$} & \multicolumn{2}{|c|}{ Small $(n=30)$} & \multicolumn{2}{|c|}{ Large $(n=30)$} & \multirow[b]{2}{*}{ t-value } \\
\hline & Mean & SD & Mean & SD & \\
\hline \multicolumn{6}{|l|}{ OSS adoption factors } \\
\hline 1. Degree of adoption & 3.6851 & 1.15253 & 3.6953 & 1.19791 & -.034 \\
\hline 2. Maturity level & 3.0600 & .94200 & 2.5800 & .9980 & $1.905^{*}$ \\
\hline 3. Experience \& skill & 2.7833 & .89475 & 2.6333 & .86536 & .660 \\
\hline 4. Selection criteria & 2.9000 & 1.03307 & 2.7000 & 0.61728 & .910 \\
\hline \multicolumn{6}{|l|}{ Success } \\
\hline Cost efficiency & 2.67 & 1.093 & 2.47 & .819 & .802 \\
\hline Productivity & 3.13 & .507 & 2.47 & .730 & $4.106^{* *}$ \\
\hline Quality & 2.87 & 1.106 & 2.67 & .606 & .869 \\
\hline
\end{tabular}

The findings from this study showed that there are no significant statistical differences between small and large sized organizations so far as OSS adoption is concerned. It is important to note that we did not study the whole organization but we concentrated on the software developers and how they adopt OSS. It is possible that the result of study might turn out to be different if we had studied the organization as a whole. All the same, judging from the results in table 15 , it is interesting to note that small sized organizations have some edge over large sized organizations with respect to maturity level and development productivity. It is difficult to try and explain this result from 
our data but this, in a way, is consistent with the study on organization size and on quality management comparing large and small firms that, while small firms implement TQM at least as effectively as large firms, they (small firms) may relied on different strategy (Lawler III, 1997), (Lerner \& Tirole, 2002). In addition, we also observed during our exploratory study interview that the motivation to adopt OSS is similar in both small and large organizations and that there is agreement when it comes to OSS adoption contribution to software development economics (cost efficiency, productivity and product quality).

\subsection{Summary}

Table 16 summarizes the results of hypothesis testing for all hypotheses proposed in this research.

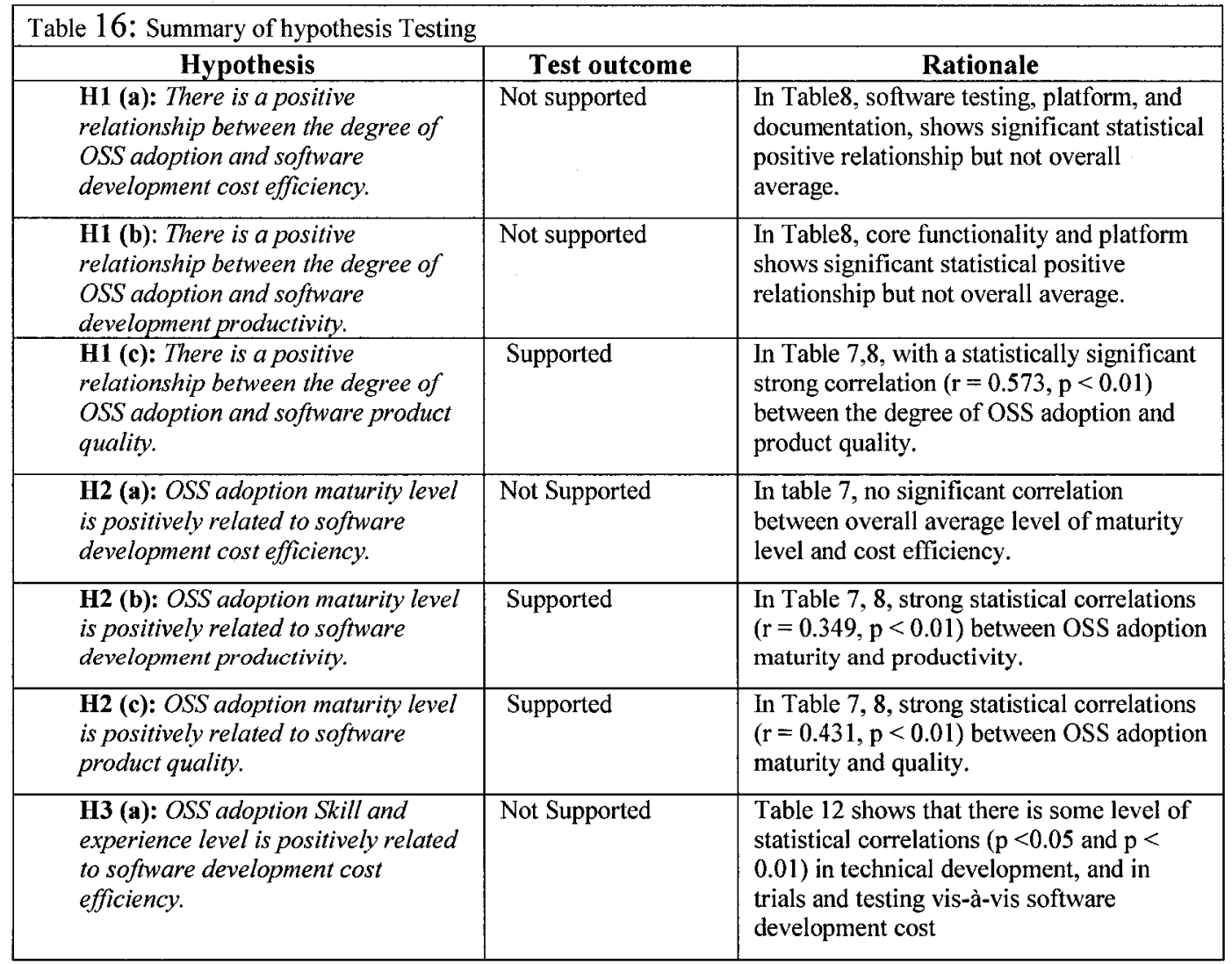




\begin{tabular}{|l|l|l|}
\hline $\begin{array}{l}\text { H3 (b): OSS adoption skill and } \\
\text { experience level is positively related } \\
\text { to software development } \\
\text { productivity. }\end{array}$ & Not Supported & $\begin{array}{l}\text { No statistical significance between } \\
\text { developers' experience on OSS adoption } \\
\text { and software development productivity }\end{array}$ \\
\hline $\begin{array}{l}\text { H3 (c): OSS adoption Skill and } \\
\text { experience level is positively related } \\
\text { to software product quality. }\end{array}$ & Supported & $\begin{array}{l}\text { Table } 7 \text { and } 12, \text { strong statistical } \\
\text { correlations }(\mathrm{r}=0.292, \mathrm{p}<0.05) \text { between } \\
\text { OSS adoption maturity and productivity. }\end{array}$ \\
\hline $\begin{array}{l}\text { H4 (a): OSS adoption selection } \\
\text { criteria are positively related to } \\
\text { software development cost efficiency. }\end{array}$ & Supported & $\begin{array}{l}\text { In table7, 13, selection criteria show very } \\
\text { high significant correlations }(\mathrm{p}<0.01) \text { with } \\
\text { cost efficiency. }\end{array}$ \\
\hline $\begin{array}{l}\text { H4 (b): OSS adoption selection } \\
\text { criteria are positively related to } \\
\text { software development productivity. }\end{array}$ & Not supported & $\begin{array}{l}\text { No significant statistical correlation } \\
\text { coefficient in any of the selection criteria } \\
\text { attributes vis-à-vis productivity (table 13) }\end{array}$ \\
\hline $\begin{array}{l}\text { H4 (c): OSS adoption selection } \\
\text { criteria are positively related to } \\
\text { software product quality. }\end{array}$ & Supported & $\begin{array}{l}\text { In table7, 13, selection criteria show very } \\
\text { high significant correlations }(\mathrm{p}<0.01) \text { with } \\
\text { product quality. }\end{array}$ \\
\hline $\begin{array}{l}\text { H5: There is difference between } \\
\text { small and large sized organizations } \\
\text { when adopting OSS }\end{array}$ & Not supported & $\begin{array}{l}\text { Table } 15 \text { shows significant difference is } \\
\text { observed in maturity level and in software } \\
\text { development productivity where small } \\
\text { organizations reported higher level of } \\
\text { effects }(\mathrm{t}=1.905, \mathrm{p}<0.05 ; \mathrm{t}=4.106, \mathrm{p}< \\
0.01) \text { than in large sized organizations. }\end{array}$ \\
\hline
\end{tabular}




\section{CONCLUSIONS, LIMITATIONS, AND FUTURE RESEARCH}

\subsection{Conclusions}

This study investigated the impacts of OSS adoption on the economics of software development. Specifically, the paper looks at the relationships between OSS adoption factors (degree of adoption, maturity level, developers' experience and skill, and selection criteria) on software development economics (cost efficiency, productivity, and quality). We started the study by conducting an exploratory study of six software organizations that are adopting OSS components. The outcome of this initial study led to the development of a questionnaire as the instrument of measurement, the development of hypotheses, and the identification of variables for the study. This report presents the empirical results of analyzing $60 \mathrm{small} /$ medium and large sized IT organizations.

Based on the results of our study, it is reasonable to conclude that there are strong correlations between OSS adoption factors and software development economics. It appears from this study that an organization can achieve some economic gains in terms of development productivity and more importantly product quality if it implements OSS adoption in a systematic way (Ajila, 2006), (Basili, \& Melo, 1996), (Hecker, 1999). It is also evident that there is little or no difference between the quality of OSS and the proprietary software. In fact, the result confirms that OSS is of highest quality. One big important lesson we learned especially from our exploratory study and contrary to the claims by some people, is that open source community is not setting a bad example in the way OSS is developed in terms of 'good practices' (Wilson, 1999). The only difference compared to commercial software development 
is that 'time to market' is not a critical issue for open source development. In summary our findings show the following.

The degree of OSS adoption is moderately high and this adoption has very strong positive impacts on software quality, moderate impacts on productivity and some level of impacts on cost efficiency especially software testing, platform, and documentation. This outcome is consistent with our initial exploratory study in the sense that there was a consensus among software developers that OSS components are of highest quality and adopting them contributes significantly to the end product quality. Also, there was agreement that reusing OSS components contribute somewhat significantly to productivity in terms of reduce time to market. However, the accord was not all that total as to the positive impacts of OSS adoption on cost efficiency in terms of cost reduction. The feeling was that OSS adoption contributes somewhat to reduction in cost overrun. There is need for more study on this issue of cost.

Our study result also confirms the previously established works on case studies and experience reports (Bonaccorsi \& Rossi, 2003), (Dedrick \& West, 2003), (Hecker, 1999), (Madanmohan \& De, 2004), (Norris, 2004), (Raymond, 1999), (Stone, 2002) on the quality and contribution of OSS to software development. In general, attributes such as platform and documentation score big in terms of positive impacts on software development economics. This outcome is not surprising because studies have shown the effects of OSS such as Linux and Apache web server on critical software development in a commercial setting (Dedrick \& West, 2003), (Fitzgerald \& Kenny, 2004), (Hecker, 1999), (Kshetri, 2004), (Leavitt, 2001), (Lerner \& Tirole, 2002), (Lussier, 2004), (Norris, 2004), (West, 2003). 
There is high level motivation in OSS adoption judging from the positive correlation between adoption maturity level and development productivity, and product quality. OSS adoption motivation is at the coordinated level (cf. appendix - section 2) where

(i) OSS adoption is rewarded,

(ii) OSS adoption planning is targeted,

(iii) Breadth of adoption is at the departmental level,

(iv) Dedicated individual is placed in charge of OSS adoption,

(v) OSS adoption is emphasized in the software design, and

(vi) There is some metrics through manual tracking (cf. table 7, mean, S.D., and extracted variance).

In general, OSS adoption motivation level is moving towards ingrained adoption level in the development process where OSS adoption is the way to do business (cf. appendix - section 2). This is confirmed by the work of Frakes and Terry (Frakes \& Terry, 1996) that "Once an organization achieves ingrained reuse, reuse becomes part of the business routine and will no longer be recognized as distinct discipline." This result is also consistent with our initial findings from the exploratory study that "OSS adoption is serious and that top management is directly involved in the adoption process by encouraging their line managers to reuse open source components."

While there is no strong statistical significance between OSS adoption skill and experience, and software development economics, there is some statistical correlation pointing to the fact that software reuse experience and skill in general is important when adopting OSS. Although this result is not as strong compared to our initial 
literature review on adoption process (Ajila, 2006), (Basili, \& Melo, 1996), (Crnkovic \& Larsson, 2002), (Frakes \& Terry, 1996), (Gaffney \& Durek, 1989), (McArthur, 2002) but, we can conclude that OSS adoption does not need a special skill and experience other than what is needed for software reuse in general. This is confirmed by the positive correlation coefficients of attributes such as technical development and testing, on cost efficiency and quality. In any case our exploratory study shows that organizations OSS adoptions do have experience in general software components reuse before switching to OSS reuse.

The result shows that the "selection criteria" is an important factor in software development cost efficiency and in product quality. This means that selection based on functional and business requirements is very important to organizations adopting OSS. As it is, we can not dismiss the impacts of technical requirements (i.e. productivity) simply because there are no significant statistical correlations between the attributes of selection criteria and productivity. More study is needed on this subject.

This study did not show any marked differences between how small sized organizations adopt OSS compared to large sized organizations. However small sized organizations show a more significant productivity compared to large sized organization. This is consistent with the study on organization size and on quality management comparing large and small firms that small firms can implement TQM at least as effectively as large firms (Lawler III, 1997), (Lerner \& Tirole, 2002). In general, our exploratory study shows that the motivation to adopt OSS components in software development is similar in both small and large sized organizations. 


\subsection{Limitations}

There are some methodological limitations in this study. Notable is the single sourcing and self reporting technique used in data gathering. Researchers have argued that studies employing single source methodology can be biased even though project/quality managers and senior developers are able to see the bigger picture and direction of the software development project. Is it then possible that the result obtained from this study will be different if sampled data are collected from individual team members? Would this not introduce a new dimension of complexity to the study? One could argue that collecting data from individual team members may reflect the same problem of single sourcing and may introduce personal preference over the 'bigger picture'. In this study, we have tried as much as possible to address this problem by carrying out an initial exploratory work on the study. Secondly, the sample size is not very large because we are interested in software organizations that are using OSS components intensively and we also have the additional requirements that imposed a minimum of 20 software developers in each organization. A problem we discovered during the analysis is that the number of software developers in the majority of the companies is relatively small in size compare to the overall size of the company. In addition, our sampling method did not allow us to calculate the response rate because we started by interviewing 18 people in six different organizations and then move to random sampling of 120 organizations, and finally selecting 75 organizations that fit our profile. In a sense this sampling approach gave us more trust in the data we obtained. Another limitation we found out during our study is that it is difficult to divorce OSS components adoption from the general software process improvement (SPI). Without SPI it is difficult to measure the success and impacts of 
reuse on software development productivity, cost efficiency and product quality (Royce, 1998). In fact, this is evidenced when comparing small and large sized organizations.

\subsection{Future research}

There is plenty of future work in this study. First, we could increase our sample by removing the boundary of having at least 20 software developers since the overwhelming majority of organizations developing software (or software group sizes within a company) are relatively small. Well, this could affect the data. Secondly, despite the empirical result confirming the literature review, there is a need for a thorough longitudinal study (Ajila \& Razvan, 2007), (Ajila \& Bailetti, 2006) on the culture of OSS adoption in small and large organizations. This means that we need to collect and analyze real life data (Ajila \& Razvan, 2007) on OSS adoption. This can be very difficult and time consuming. Thirdly, impact of OSS adoption research should be related to the study of improved measures of SPI success. Finally, the impacts of OSS components adoption on cost of software development need to be studied separately. Cost and time to market are two major factors in software development economics. It has been established that (proprietary) software reuse in general contributes to reduction in time to market as well as cost. Can we say the same thing for OSS adoption? This type of study is even more important because some people believe that the short term gains in cost reduction by adopting OSS components is a long term spending on maintenance and security. 


\section{REFERENCES}

Ahire, S. L. and Golhar, D. Y.1996.Quality Management in Large vs. Small Firms: An Empirical Investigation, Journal of Small Business Management, Vol. 34, No. 2 pp $1-13$

Ajila, Samuel A. and Wu, Di 2007 Empirical Study of the Effects of Open Source Adoption on Software Development Economics, The Journal of Systems and Software (2007), doi:10.1016/j.jss.2007.01.011 March 2, 2007 http://www.sciencedirect.com/science/journal/01641212

Ajila, Samuel A. and Razvan T. 2007. Dumitrescu, Experimental use of code delta, code churn, and rate of change to understand software product line evolution, The Journal of Systems and Software 80 (2007) pp 74-91

Ajila, Samuel A. and Bailetti, J. A. 2006. Measuring change in software product line an experience report, International Journal of Product Development (IJPD), Vol. 3. No. 2 .

Ajila, Samuel A. 2006. The Impact of Firm Size on Knowledge Reuse and Exploration during Software Product Development: an Empirical Study, 2006 IEEE International Conference on Information Reuse and Integration (IEEE IRI2006), pp 160 - 165, Sep 16-18, 2006, Waikoloa, Hawaii, USA

Applewhite, A. 2003. Should governments go open source? Software, IEEE, Volume: 20, Issue: 4, July-Aug. pp $88-91$. 
Banker, R. D.Kauffman, R. J.1991. Reuse and Productivity in Integrated ComputerAided Software Engineering: An Empirical Study. MIS Quarterly 15(3):pp 374401.

Basili, V. R. Briand L. C. Melo, W. L. 1996. How Reuse Influences Productivity in Object-Oriented Systems. Communications of the ACM 39(10): pp104-116.

Ballmer, S. 2004. Customer Focus: Comparing Windows with Linux and UNIX, Microsoft Corporation. October 2004. http://www.center.hu/center/0234160.html

Boehm, B. W. 1981. Software Engineering Economics, Prentice-Hall, Englewood Cliffs, New Jersey, 1981.

Bokhari, S.N. 1995. The Linux operating system, Computer ,Volume: 28 , Issue: 8 , Aug. 1995 pp $74-79$.

Bonaccorsi, A. and Rossi, C. 2003. Why Open Source software can succeed, Research Policy 32, pp1243-1258

Bonaccorsi, A. Rossi, C. 2005. Licensing schemes in the production and distribution of open source software. An empirical investigation. http://opensource.mit.edu/papers/bnaccorsirossilicense.pdf.

Carlile P. R. and Christensen, C.M. 2005. The Cycles of Theory Building in Management Research. Unpublished manuscript. 
Crnkovic, I. Larsson, M. 2002. Challenges of component-based development, The Journal of Systems and Software 61 pp 201-212.

Conte, S.D., Dunsmore, H.E., Shen, V.Y. 1986. Software Engineering Metrics and Models, The Benjamin/Cummings, 1986.

Crnkovic, I. Larsson, M.2002. Challenges of component-based development, The Journal of Systems and Software 61 pp 201-212.

Dedrick, J. and West, J. 2003. Why Firms Adopt Open Source Platforms: A Grounded Theory of Innovation and Standards Adoption. MIS Quarterly Special Issue on Standard Making: A critical Research frontier for information systems, Seattle, December pp 236-257

Devanbu, P. Karstu, s. Melo,W. Thomas, W. 1996 Analytical and Empirical Evaluation of Software Reuse Metrics* IEEE, Proceedings of ICSE-18 0270$5257 / 96$.

Derick, J. West, J. 2003. Why firms adopt Open Source platforms: A grounded theory of innovation and standards adoption. MIS Quarterly Special Issue Work shop on Standard Making: A critical research frontier for information systems. Seattle, December 2003. http://www.si.umich.edu/misq-stds/proceedings/145 236257.pdf Workshop home page: http://www.si.umich.edu/misqstds/proceedings/index.html.

El Emam, K.2001. Ethics and Open Source, Empirical Software Engineering, Kluwer Academic Publishers, 6(4):pp 291-292

El Emam, K.2005. The ROI from Software Quality, CRC Press, ISBN 0849332982 
Eisenhardt, K. M. 1989. Building Theories from Case Study Research. Academy of Management Review 14(4): pp 532-550.

Fichman, R. G. and Kemerer, C. F. 1997. The assimilation of software process innovations: An organizational learning perspective, Management Science, 43, 10,1345 .

Fitzgerald, B. 2004. A critical look at open source, Computer ,Volume: 37 , Issue: 7 , July 2004 pp $92-94$.

Fitzgerald, B.; Kenny, T. 2004.Developing an Information Systems Infrastructure with Open Source Software, Software, IEEE. Volume: 21, Issue: 1, Jan-Feb, pp $50-55$

Foley, M. J. 2002. E*Trade Bets Big on Linux, http://www.baselinemag.com/article2/0,3959,15844,00.asp, accessed February 22, 2004.

Franck, E. and Jungwirth, C. 2003. Reconciling Rent-Seekers and Donators - The Governance Structure of Open Source, Journal of Management \& Governance, 7 , 4,401 .

Frakes, W.B. and Fox, C. J.1996. Software Reuse: Metrics and Models. ACM Computing Surveys 28(2), June

Frakes, W. B. Fox, C. J. 1995. Sixteen Questions About Software Reuse. Communications of the ACM 38(6). 
Franke, N. Hippel, V. E. .2003. Satisfying heterogeneous user needs via innovation toolkits: the case of Apache security software. Research Policy. Volume: 32, Issue: 7. July, 2003. pp 1199-1215.

Gabriel R. P. Goldman R. 2002. Open source: beyond the fairytales. http://opensource.mit.edu/papers/gabrielgoldman.pdf.

Gacek, C., Arief, B. 2004. The Many Meanings of Open Source, IEEE Software, Volume: 21, Issue: 1 , Jan-Feb, pp $34-40$.

Gaffney, J. E. Durek, T. A. 1989. Software reuse - key to enhanced productivity: some quantitative models Information and Software Technology 31(5): pp 258267.

Glass, R.L. 1999. The Loyal Opposition of Open Source, Linux...and hype, Software, IEEE, Volume: 16, Issue: 1, Jan.-Feb. 1999, pp 126-128.

Godfrey, M. W. Tu, Q. 2000. Evolution in open source software: A case study. Proceedings 2000 International Conference. Software Maintenance (ICSM-00), San Jose, California.

Gottlieb, S 2006. How to choose an open-source CMS, ZDNet, 25 January, 02:27 PM

Gu, M.2004. Conversational Case-Based Reasoning in Software Component Reuse, Research Description and Plan Norwegian University of Science and Technology 
Hall, P.A.V. 1999.Architecture-driven component reuse, Information and Software Technology 41 pp 963-968.

Haber, L. 2002. Store chain is sold on Linux, http://techupdate.zdnet.com/techupdate/stories/main/0,14179,2841690,00.html, accessed February 22, 2004.

Hecker, F. 1999. Setting up Shop: The Business of Open-Source Software, Software, IEEE, Volume: 16, Issue: 1, Jan.-Feb. pp $45-51$.

Hickman, A. 2004. How Do You Decide If OSS Works for You? NonProfit Open Source Initiative http://www.nosi.net/node.

Hunt, A.; Thomas, D. 2002. Software archaeology, Software, IEEE ,Volume: 19 , Issue: 2 , March-April 2002 pp $20-22$.

Kan, S. H. 2003. Metrics and Models in Software Quality Engineering, $2^{\text {nd }}$ Edition. Addison-Wesley press, Chap 4.

Koltun, P. and Hudson, A.1991. A reuse maturity model. In Fourth Annual Workshop on Software Reuse, Herndon, VA

Kshetri, N. 2004. Economics of Linux Adoption in Developing Countries, Software, IEEE, Volume: 21, Issue: 1, Jan-Feb pp $74-81$.

Lakhani, K. R., Wolf, B., Bates, J. and DiBona, C. 2002. The Boston Consulting Group Hacker Survey, O'Reilly Open Source Conference, San Diego, CA. 
Laird, C. 2002. Open source in the lab, IBM. 01 Oct 2002. http://www106.ibm.com/developerworks/linux/library/l-oslab/.

Lattanzi, M. and Henry, S.1998.Software reuse using C++ classes: The question of inheritance, The Journal of Systems and Software 41 (1998) pp 127-132.

Lawler III, E. E.1997.Rethinking Organizational Size, Organization Dynamics, 1997. Vol. 26, No. 2, pp 24-35.

Lawton, G. 2002. Open Source Security: Opportunity or Oxymoron? Computer, Volume: 35, Issue: 3 , March, pp $18-21$.

Leavitt, N. 2001. Linux: at a Turning Point? Computer, Volume: 34, Issue: 6, June. pp $12-15$.

Lerner, J. and Tirole, J. 2002. The Scope of Open Source Licensing. http://www.people.hbs.edu/jlerner/OSLicense.pdf.

Lerner, J. and Tirole, J. 2002. Some Simple Economics of Open Source, Journal of Industrial Economics, June, Vol. 50 Issue 2, pp 197-234.

Lewis, T. 1999. The Open Source Acid Test, IEEE Computer Society, February (Vol. 32, No. 2) pp 125-128.

Lussier, S. 2004. New tricks: how open source changed the way my team works, Software, IEEE, Volume: 21, Issue: 1, Jan-Feb 2004, pp 68 - 72. 
Macedonia, M. 2001. Will Linux be computer games' dark horse OS? Computer, Volume: 34, Issue: 12, Dec. 2001 pp $161-162$.

Madanmohan, T.R. and De, R. 2004. Open Source Reuse in Commercial Firms, Software, IEEE, Volume: 21, Issue: 6, Nov.-Dec. pp $62-69$.

McArthur, K. 2002. An evaluation of the impact of component-based architectures on software reusability, Information and Software Technology, 44 pp 351-359.

Messerschmitt, D.G. 2004. Marketplace issues in software planning and design, Software, IEEE, Volume: 21, Issue: 3, May-June 2004, pp 62 - 70 .

Mili, H.2003. An experiment in software component retrieval, Information and Software Technology 45 pp 633-649.

Murrain, M. 2004. Choosing and Using Open Source Software: A Primer for Nonprofits, NOSI (Nonprofit Open Source Initiative).

Netcraft LTD .2003. November 2003 Web Server Survey, http://news.netcraft.com/archives/web_server_survey.html, accessed November 14, 2003.

Microsoft Corporation .2004. Microsoft Customer Evidence: Equifax Case study. Microsoft Corporation. June 2004. http://www.microsoft.com/resources/casestudies/CaseStudy.asp?CaseStudyID=1 5528. 
Norris, J.S. 2004. Mission-critical development with open source software: lessons learned, IEEE Software, Volume: 21, Issue: 1, Jan-Feb 2004, pp 42- 49.

Open Source Development Network, Inc. 2003. http://sourceforge.net/.

Open Source Initiative (OSI), The Open Source Definition. Version 1.9, 2006, available on: http://www.opensource.org/docs/definition

Ortiz, S., Jr. 2001. Embedded OSS gain the inside track, Computer, Volume: 34, Issue: 11 , Nov. 2001 pp $14-16$.

Pearson, H.E. 2000. Open source license: Open Source-The death of preparatory system? Computer Law and Security Report, Volume: 16, Issue: 3, June 1, pp. 151-156.

Poulin, J. S.1997. Measuring Software Reuse: principles, practices, and economic models. Reading, MA, Addison-Wesley.

Pressman, R. S. 1997. Software Engineering: A Practitioner's Approach, 4th Edition. McGraw Hill press, Chap 4.

Prieto-Diaz, R.1993. Status report: software reusability, Software, IEEE, Volume 10, Issue 3, May 1993, pp $61-66$.

Raymond, E. 1999. Linux and Open - Source Success, Software, IEEE, Volume: 16, Issue: 1, Jan.-Feb. 1999, pp $85-89$. 
Richardson, I.2001. Software Process Matrix: A Small Company SPI Model, Software Process Improvement and Practice, Vol. 6, No. 3, pp. 157-165

Rothenberger, M. A. Hershauer, J. C.1998.: Facilitating the Retrieval of Reusable Software Components using an Enterprise-Level Model. Proceedings of the Association for Information Systems Americas Conference, August 1998.

Royce, W. 1998. Software Project Management - A Unified Framework, Addison Wesley. ISBN 0201309580.

Ruffin, M. Ebert, C. 2004. Using Open Source Software in Product Development: A Primer, IEEE Software, Volume: 21, Issue: 1, Jan-Feb, pp $82-86$.

Scacchi, W. 2004. Free and Open Source Development Practices in the Game Community, Software, IEEE, Volume: 21, Issue: 1, Jan-Feb, pp 59-66.

Spinellis, D.; Szyperski, C. 2004. How is Open Source Affecting Software Development? IEEE Software, Volume: 21, Issue: 1, Jan-Feb, pp 28- 33.

Spinellis, D. Raptis, K.2000. Component Mining: a process and its pattern language, Information and Software Technology 42 pp 609-617

SPMN.2003. 16 Critical Software Practices The Road to Performance-Based Management, The Software Program Managers Network http://www.iceincusa.com/16CSP/content/hmfrm.htm 
Stone, A. 2002. Open Source Acceptance Grows, Software, IEEE, Volume: 19, Issue: 2, March-April 2002, pp $102-102$.

Thomas, D. and Hunt, 2004. A. Open source ecosystems, Software, IEEE, Volume: 21, Issue: 4, July-Aug. pp $89-91$.

Voth, D. 2003. Open Source in the US Government, Software, IEEE, Volume: 20, Issue: 1, Jan.-Feb. pp $73-73$.

Wall, D.A.E. 2001. Using Open Source for a Profitable Startup, Computer, Volume: 34, Issue: 12, Dec. pp $158-160$.

Wang, H. and Wang, C. 2001. Open Source Software Adoption: A Status Report, Software, IEEE, Volume: 18, Issue: 2, March-April, pp 90-95.

West, J. 2003. How open is open enough? - Melding proprietary and open source platform strategies. Research Policy, Volume: 32, Issue: 7. July, pp 1259-1285.

Wilson, G. 1999. Is the Open-Source Community Setting a bad example? Software, IEEE, Volume: 16, Issue: 1, Jan.-Feb. pp 23-25.

Witten, B., Landwehr, C. and Caloyannides, M. 2001. Does Open Source Improve System Security? Software, IEEE, Volume: 18, Issue: 5, Sept.-Oct. pp $57-61$. 
Wu, M.W. and Lin, Y.D. 2001. Open source Software Development: An Overview, IEEE Computer Society, June, Vol.34, No. 6, pp $33-38$. 


\section{APPENDIX}

Appendix A: Letter of information

\section{Dear Sir/Madam:}

My name is Di Wu. I'm a graduate student in Telecommunication and Technology Management (TTM), Department of Systems and Computer Engineering, Carleton University, Canada. I'm doing a research study to identify 'how using Open Source software affects software project development', and investigating how different factors in the use of Open Source software affect software development performance. I invite you to participate in this research study by answering the questions listed in the attached questionnaire.

This questionnaire has been designed so you could complete and return it electronically by e-mail. Once you have completed the questionnaire, save your answers and attach the file as a reply to the e-mail sent to you originally. To complete the questionnaire, please select a completed software development project in which you were involved in the past three years. If the project involved more than developing a software product (e.g. developing a hardware product), please focus on the software development aspects of the project and the team responsible for developing the software product.

This questionnaire should take you less than 25 minutes to complete. Most of the questions are focused on how OSS is used in a specific software development project in your company. You may decline answering any question(s) in the questionnaire.

Because the questionnaire is being distributed and returned via e-mail there are risks of eavesdropping and invasion of privacy. Encryption technology can be used to secure E-mail communications. 
You are not required to provide your names, other personal information and identifiable information about your company to us. In any case I will delete any identifier in your e-mail to protect your anonymity. However, if you allow us to contact you when additional information is required, please provide your contact information, which is in separate page at the end of questionnaire in order to protect anonymity.

The information you provide will be used only in aggregate form. Only my supervisor and I can access such data. That data will be saved in the researcher's flash disk with encryption until the time the research is completed, which is expected to be in June 2006. After that, the data will be deleted permanently.

The time and effort you take to participate in this research study is appreciated, but you may not benefit from your participation in the study. After the study, a copy of the research results will be sent to you upon request by e-mail.

Should you have any questions about this research study or wish to withdraw from it, feel free to contact me at+1 613 520-2600 Ext.8644, or Di_Wu@Carleton.Ca by e-mail. My supervisor, Dr. Samuel A. Ajila, can be reached at $+1613520-2600$ Ext. 2673, or Samuel.Ajila@sce.carleton.ca by e-mail.

This research has been reviewed and received ethics clearance through the Carleton University Research Ethics Committee. Should you have any concerns or questions about your involvement in this research study, please contact:

Carleton University Research Ethics Committee

511A Tory Carleton University

Tel: $+1613520-2517$

Thanks very much for your time and cooperation.

Di Wu

Di_Wu@Carleton.ca

Tel: +1 613 520-2600 Ext.8644
Supervisor: Dr. Samuel A. Ajila

Samuel.Ajila@sce.carleton.ca

Tel: +1613 520-2600 Ext. 2673 
Appendix B: Questionnaire

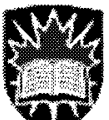

\section{Carleton \\ UNIVERSITY}

\section{5, Colonel by Drive, Ottawa, Ontario, K1S 5B6, Canada}

Objective of the Research:

The goal of this research is to identify and measure the effects of using Open Source software (OSS) on the economics of software development.

Instructions:

Please answer the following questions based on one software development project in which Open Source software has been adopted and of which you have in-depth knowledge.

This questionnaire should take a maximum of 25 minutes to complete. You may save your answers and attach the file as a reply to Di_Wu@carleton.ca.

Questions about the survey process or content should be directed to: Di Wu(a)carleton.ca (Mrs. Di Wu) or Ajila@sce.carleton.ca (Dr. Samuel A. Ajila)

All responses will be kept strictly confidential. The research results will be sent to you once they are available.

Thank you for your time and cooperation.

\section{Section 1 - Degree of Open Source Software Adoption}

1. Compared to your company's other project how high was the degree of Open Source software adopted in this project? Please check the appropriate box for each of the following dimensions.

\begin{tabular}{|l|c|c|c|c|c|c|c|}
\hline $\begin{array}{l}\text { How high was the degree of OSS } \\
\text { adoption in }\end{array}$ & $\begin{array}{c}\text { Not } \\
\text { Sure }\end{array}$ & $\begin{array}{c}\text { Not } \\
\text { at } \\
\text { all }\end{array}$ & Rarely & Moderately & $\begin{array}{c}\text { Moderately } \\
\text { High }\end{array}$ & High & $\begin{array}{c}\text { Very } \\
\text { High }\end{array}$ \\
\hline SW testing & $1 \square$ & $2 \square$ & $3 \square$ & $4 \square$ & $5 \square$ & $6 \square$ & $7 \square$ \\
\hline Core functional components & $1 \square$ & $2 \square$ & $3 \square$ & $4 \square$ & $5 \square$ & $6 \square$ & $7 \square$ \\
\hline Platforms & $1 \square$ & $2 \square$ & $3 \square$ & $4 \square$ & $5 \square$ & $6 \square$ & $7 \square$ \\
\hline Design Patten & $1 \square$ & $2 \square$ & $3 \square$ & $4 \square$ & $5 \square$ & $6 \square$ & $7 \square$ \\
\hline Tools & $1 \square$ & $2 \square$ & $3 \square$ & $4 \square$ & $5 \square$ & $6 \square$ & $7 \square$ \\
\hline Product's architecture & $1 \square$ & $2 \square$ & $3 \square$ & $4 \square$ & $5 \square$ & $6 \square$ & $7 \square$ \\
\hline Document and process & $1 \square$ & $2 \square$ & $3 \square$ & $4 \square$ & $5 \square$ & $6 \square$ & $7 \square$ \\
\hline Other & $1 \square$ & $2 \square$ & $3 \square$ & $4 \square$ & $5 \square$ & $6 \square$ & $7 \square$ \\
\hline Other & $1 \square$ & $2 \square$ & $3 \square$ & $4 \square$ & $5 \square$ & $6 \square$ & $7 \square$ \\
\hline
\end{tabular}

Section 2 - Selection Criteria in the Development Process

2. Compare three selection criteria described in the following choices and choose which ones are more often used by your development team to select Open Source software.

a) $\square$ Selection based on functional requirements- such as efficiency, speed of execution, organization standards or preference

b) $\square$ Selection based on technical requirement - such as availability of technical support, future upgrade, customization, and reliability 
c) $\square$ Selection based on management requirements - such as cost efficiency issues,

development team experience, license, or maintainability, familiarity or referral was the main attribute to be considered most of the time

d) Other:

(Please Sepcify)

3. How important was the selection criteria (mentioned in Question 2) in each of the four software development activities? Check the appropriate box for each activity.

\begin{tabular}{|l|c|c|c|c|c|}
\hline \multirow{2}{*}{$\begin{array}{l}\text { Software Development } \\
\text { Activities }\end{array}$} & \multicolumn{5}{|c|}{ OSS Selection Criteria } \\
\cline { 2 - 6 } & $\begin{array}{c}\text { Not } \\
\text { Sure }\end{array}$ & $\begin{array}{c}\text { Not } \\
\text { Important }\end{array}$ & $\begin{array}{c}\text { Somewhat } \\
\text { Important }\end{array}$ & $\begin{array}{c}\text { Very } \\
\text { Important }\end{array}$ \\
Important
\end{tabular}

\section{Section 3 - OSS Adoption Maturity Level}

4. What are the motivation levels for adopting Open Source software? Check the appropriate boxes.

\begin{tabular}{|c|c|c|c|c|c|}
\hline \multirow{3}{*}{$\begin{array}{l}\text { Motivation/Culture } \\
\text { of Adoption }\end{array}$} & \multicolumn{5}{|c|}{ OSS Adoption Motivation Levels } \\
\hline & \multicolumn{2}{|c|}{\begin{tabular}{l|l} 
Initial/Chaotic & Monitored \\
\end{tabular}} & Coordinated & Planned & Ingrained \\
\hline & $\begin{array}{c}\square \\
\text { Discouraged }\end{array}$ & $\begin{array}{c}\square \\
\text { Encouraged }\end{array}$ & $\begin{array}{c}\square \\
\begin{array}{c}\text { Re-enforced } \\
\text { rewarded }\end{array}\end{array}$ & $\begin{array}{c}\square \\
\text { Indoctrinated }\end{array}$ & $\begin{array}{c}\square \\
\text { Is the way do } \\
\text { business }\end{array}$ \\
\hline $\begin{array}{l}\text { Planning for } \\
\text { Adoption }\end{array}$ & $\underset{\text { None }}{\square}$ & $\begin{array}{c}\square \text { Grassroots } \\
\text { Activity }\end{array}$ & $\begin{array}{c}\square \\
\text { Targets of } \\
\text { Opportunity }\end{array}$ & $\begin{array}{c}\square \\
\text { Business } \\
\text { imperative }\end{array}$ & $\begin{array}{c}\square \\
\text { Part of Strategic } \\
\text { Plan }\end{array}$ \\
\hline $\begin{array}{l}\text { Breadth of } \\
\text { Adoption }\end{array}$ & $\begin{array}{c}\square \\
\text { Individual }\end{array}$ & $\begin{array}{c}\square \\
\text { Work Group }\end{array}$ & $\begin{array}{c}\square \\
\text { Department }\end{array}$ & $\square_{\text {Division }}^{\square}$ & $\begin{array}{c}\square \\
\text { Enterprise Wide }\end{array}$ \\
\hline $\begin{array}{l}\text { Responsible for } \\
\text { Making Adoption } \\
\text { Happen }\end{array}$ & $\begin{array}{c}\square \\
\text { Individual } \\
\text { Initiative }\end{array}$ & $\begin{array}{c}\square \\
\text { Shared } \\
\text { Initiative }\end{array}$ & $\begin{array}{c}\square \\
\text { Dedicated } \\
\text { Individual }\end{array}$ & $\begin{array}{c}\square \\
\text { Dedicated } \\
\text { Group }\end{array}$ & $\begin{array}{c}\square \\
\text { Corporate Group } \\
\text { with Division } \\
\text { Liaisons }\end{array}$ \\
\hline $\begin{array}{l}\text { Process by Which } \\
\text { Adoption is } \\
\text { Leveraged }\end{array}$ & $\begin{array}{c}\square \\
\text { Adoption } \\
\text { Process } \\
\text { Chaotic, } \\
\text { Unclear how } \\
\text { Adoption } \\
\text { Comes in. }\end{array}$ & $\begin{array}{c}\square \\
\text { Adoption } \\
\text { Questions } \\
\text { Raised at } \\
\text { Design } \\
\text { Reviews (After } \\
\text { the fact) }\end{array}$ & $\begin{array}{c}\square \\
\text { Design } \\
\text { emphasis } \\
\text { placed on OSS } \\
\text { Adoption }\end{array}$ & $\begin{array}{c}\square \\
\text { Focus on } \\
\text { developing } \\
\text { families of } \\
\text { projects }\end{array}$ & $\begin{array}{c}\square \\
\text { All software } \\
\text { projects are } \\
\text { generic for future } \\
\text { OSS Adoption }\end{array}$ \\
\hline $\begin{array}{l}\text { Metrics of } \\
\text { Adoption }\end{array}$ & $\begin{array}{c}\square \\
\text { No Metrics on } \\
\text { Adoption } \\
\text { Level, pay- } \\
\text { off, or costs }\end{array}$ & $\begin{array}{c}\square \\
\text { Number of } \\
\text { Lines of code } \\
\text { used in cost } \\
\text { models }\end{array}$ & $\begin{array}{c}\square \\
\text { Manual } \\
\text { tracking of } \\
\text { adoption } \\
\text { occurrences of } \\
\text { catalog parts }\end{array}$ & $\begin{array}{l}\square \\
\text { Analyses done } \\
\text { to identify } \\
\text { expected } \\
\text { payoffs from } \\
\text { developing } \\
\text { reusable parts }\end{array}$ & $\begin{array}{c}\square \\
\text { All System } \\
\text { Utilities, software } \\
\text { tools and } \\
\text { accounting } \\
\text { mechanisms } \\
\text { instrumented to } \\
\text { track adoption }\end{array}$ \\
\hline
\end{tabular}

\section{Section 4 - Skill and Experience}

5. What are the experience and skill level of the people using Open Source software during each of the four activities of the software development process? Check the appropriate box for each activity. 


\begin{tabular}{|l|c|c|c|c|c|}
\hline \multirow{2}{*}{\begin{tabular}{l} 
Development \\
\cline { 2 - 6 }
\end{tabular}} & $\begin{array}{c}\text { Not } \\
\text { Sure }\end{array}$ & $\begin{array}{c}\text { Beginner } \\
\text { (late } \\
\text { majority/ } \\
\text { traditionalist) }\end{array}$ & $\begin{array}{c}\text { Intermediate } \\
\text { (early } \\
\text { majority) }\end{array}$ & $\begin{array}{c}\text { Advanced } \\
\text { (early } \\
\text { adopter) }\end{array}$ & $\begin{array}{c}\text { Expert } \\
\text { (innovator) }\end{array}$ \\
\hline $\begin{array}{l}\text { Idea generation and } \\
\text { screening }\end{array}$ & $1 \square$ & $2 \square$ & $3 \square$ & $4 \square$ & $5 \square$ \\
\hline $\begin{array}{l}\text { Requirements } \\
\text { definition and design } \\
\text { specification }\end{array}$ & $1 \square$ & $2 \square$ & $3 \square$ & $4 \square$ & $5 \square$ \\
\hline $\begin{array}{l}\text { Technical } \\
\text { development }\end{array}$ & $1 \square$ & $2 \square$ & $3 \square$ & $4 \square$ & $5 \square$ \\
\hline Trials and testing & $1 \square$ & $2 \square$ & $3 \square$ & $4 \square$ & $5 \square$ \\
\hline
\end{tabular}

\section{Section 5 - Project Outcome Measures}

6. Rate the degree to which the project met specific performance objectives. Check the appropriate box for each objective.

\begin{tabular}{|l|l|l|l|l|l|}
\hline $\begin{array}{l}\text { To what extent has } \\
\text { this project }\end{array}$ & $\begin{array}{l}\text { Cannot } \\
\text { Rate }\end{array}$ & $\begin{array}{l}\text { Below } \\
\text { Expectation }\end{array}$ & On Target & $\begin{array}{l}\text { Above } \\
\text { Target }\end{array}$ & $\begin{array}{l}\text { Exceeded all } \\
\text { Expectations }\end{array}$ \\
\hline $\begin{array}{l}\text { Met cost efficiency } \\
\text { goals }\end{array}$ & $1 \square$ & $2 \square$ & $3 \square$ & $4 \square$ & $5 \square$ \\
\hline $\begin{array}{l}\text { Met productivity } \\
\text { goals }\end{array}$ & $1 \square$ & $2 \square$ & $3 \square$ & $4 \square$ & $5 \square$ \\
\hline $\begin{array}{l}\text { Met quality } \\
\text { specifications }\end{array}$ & $1 \square$ & $2 \square$ & $3 \square$ & $4 \square$ & $5 \square$ \\
\hline
\end{tabular}

7. What type of programming language used in coding the system
a) Java
b) $\mathrm{C}++$
c) 4th Generation Script Language
d) Other:

(Please Sepcify)

8. The size of the project: in Lines of Code (LOC)

$\mathrm{OR} \quad$ in Function Points (FP)

9. If LOC is used and in case of more than one programming languages, could you please separate the lines of code (LOC) based on each programming language:
Java
$\mathrm{C}++$
Script language
other

10. The numbers of the errors ( $=$ errors before release) and defects ( $=$ errors after release) found in the final product:

The numbers of errors

The numbers of defects

11. (Optional) From product conception to product launch, how long did this project take? months

12. (Optional) Approximately how much money did your organization invest in this project? $\$$

\section{Section 6 - Company Information}

13. Company name: (optional) 
14. Approximate number of total employees in your company:
$\square$ Under 100
$\square 101-500$
$\square 501-1000$
$\square 1001-5000$
$5,001-10,000$
$\square 10,001+$

15. Approximate annual revenues:
$\square$ Under \$1 million
$\square \$ 1-\$ 10$ million
$\$ 10$ million - $\$ 50$ million
$\square \$ 100$ million - $\$ 500$ million
$\$ 50$ million - $\$ 100$ million
$\square 500$ million +

16. Position of the respondant in the company:

$\begin{array}{ll}\square \text { Project Manager } & \square \text { Team Leader } \\ \square \text { System/Software Engineer } & \square \text { Developer/Programmer }\end{array}$

Oothers:

(Please Sepcify)

Contact Information (optional)

Should I require any additional information, I may need to contact you personally.

Your name: (Optional)

Title:

Phone: ( Fax: (Optional)

E-mail

Please check here $\square$ if you wish to receive a copy of the research results

Thank you again for your time and cooperation. 